\title{
POLÍTICA PÚBLICA, DESENVOLVIMENTISMO NEOEXTRATIVISTA E A COSMOVISÃO INDÍGENA: O POLÊMICO PROJETO DA RODOVIA CORTANDO O TIPNIS NA BOLÍVIA
}

\author{
PUBLIC POLICIES, NEOEXTRATIVIST DEVELOPMENT AND INDIAN \\ COSMOVISION: THE POLITICAL PROJECT OF THE HIGHWAY CUTTING \\ TIPNIS IN BOLIVIA
}

\section{POLITICAS PÚBLICAS, DESENVOLVIMIENTO NEOEXTRATIVISTA Y COSMOVISION INDIGENA: EL POLÍMICO PROYECTO DE LA RODOVÍA CORTANDO EL TIPNIS EN BOLÍVIA}

\author{
LITON LANES PILAU SOBRINHO \\ https://orcid.org/0000-0001-5696-4747 / http://lattes.cnpq.br/2413013286462855 / litonlanes@gmail.com \\ Universidade de Passo Fundo, UPF. \\ Passo Fundo, RS, Brasil. \\ Universidade do Vale do Itajaí, UNIVALI. \\ Itajaí, SC, Brasil. \\ Cleide Calgaro \\ https://orcid.org/0000-0002-1840-9598 / http://lattes.cnpq.br/8547639191475261 / ccalgaro1@hotmail.com \\ Universidade de Caxias do Sul, UCS. \\ Caxias do Sul, RS, Brasil.
}

THIAGO DOS SANTOS DA SILVA https://orcid.org/0000-0002-8889-9852 / http://lattes.cnpq.br/8718260756783437 / thiagodyow@yahoo.com.br Universidade de Caxias do Sul, UCS.

Caxias do Sul, RS, Brasil.

\begin{abstract}
RESUMO
O presente artigo analisa o projeto da rodovia proposto por Evo Morales, como forma de desenvolvimento, verificando os riscos e problemas socioambientais causados aos indígenas e ao meio ambiente. Para tal é utilizado o método analítico dedutivo tendo como base estudos bibliográficos. Desta forma, entende-se que o Governo de Evo Morales pregava a renúncia do modelo de desenvolvimento eurocêntrico, mas com a criação da rodovia cortando o TIPNIS está implementando políticas públicas de cunho colonial e neoextrativista.
\end{abstract}

Palavras-chave: Constitucionalismo Latino-americano; Desenvolvimento neoextrativista; Indígenas; Políticas Públicas.

\section{ABSTRACT}

This article analyzes the highway project proposed by Evo Morales, as a way of development, verifying the risks and socioenvironmental problems caused to the indigenous population and to the environment. For this the deductive analytical method is used, based on bibliographical studies. Therefore, it is understood that the Government of Evo Morales preached the renunciation of the eurocentric development model, but with the creation of the highway cutting the TIPNIS is implementing public policies of colonial and neo-extractivist nature.

Keywords: Latin American constitutionalism; neo-extractive development; indigenous peoples; public policies. 


\section{RESUMEN}

El presente artículo analiza el proyecto de la carretera propuesto por Evo Morales, como forma de desarrollo, verificando los riesgos y problemas socioambientales causados a los indígenas y al medio ambiente. Para ello se utiliza el método analítico deductivo teniendo como base estudios bibliográficos. De esta forma, se entiende que el Gobierno de Evo Morales predicaba la renuncia del modelo de desarrollo eurocéntrico, pero con la creación de la carretera cortando el TIPNIS está implementando políticas públicas de carácter colonial y neoextrativista.

Palabras clave: constitucionalismo latinoamericano; desarrollo neoextrativista; indígena; políticas públicas.

\section{SUMÁRIO}

INTRODUÇAO; 1 TERRITÓRIO INDÍGENA E PARQUE NACIONAL ISIBÓRO SÉCURE COMO ÁREA INTANGÍVEL; 2 COSMOVISÃO INDÍGENA, BUEN VIVIR E AMBIENTE ECOLOGICAMENTE EQUILIBRADO VERSUS DESENVOLVIMENTO NEOEXTRATIVISTA E CRESCIMENTO ECONÔMICO; 3 LA CARRETERA INFAME: A FALÁCIA DO CRESCIMENTO ECONÔMICO COMO DESENVOLVIMENTO; CONCLUSÃO; REFERÊNCIAS.

\section{INTRODUÇÃO}

Desde o processo constitucional revolucionário de 2009, promovido por Evo Morales e pelo MAS (Movimiento al Socialismo, partido de base do Governo Morales), que refundou a Bolívia como Estado Plurinacional, observam-se profundas alterações nas políticas implementadas pelo Estado boliviano. Eleito com grande força popular, especialmente de comunidades originárias e campesinas, Evo Morales representou a chegada ao poder daqueles que, mesmo representando mais de metade da população boliviana, jamais haviam ocupado a principal cadeira do executivo boliviano.

Entretanto, mesmo sendo o primeiro presidente boliviano com descendência indígena, e tendo como proposta de governo um distanciamento de práticas extrativistas de desenvolvimentismo eurocêntrico, Evo Morales apresentou alguns projetos polêmicos, que geraram forte oposição, inclusive dos setores indígenas e campesinos da população. Um dos principais pontos de cisão entre a população boliviana originária e o governo Morales se deu a partir de 2011, com o projeto de construção de uma rodovia ligando Villa Tunari a San Ignacio de Moxos, com mais de 300 km de extensão, prevista para atravessar o Território Indígena e Parque Nacional Isibóro Sécure - TIPNIS, área intangível desde os anos 1990, e território de origem de diversas comunidades indígenas originárias bolivianas.

Desde o oferecimento da proposta de projeto de rodovia, foram diversas as manifestações contrárias à obra, com a justificativa que o Governo, eleito com discurso contrário ao desenvolvimentismo neoliberal, estaria, em verdade, rendendo-se ao neoextrativismo, já que tal rodovia serviria para escoar produção brasileira, já que serviria para 
ISSN 1981-3694

(DOI): $10.5902 / 1981369438606$

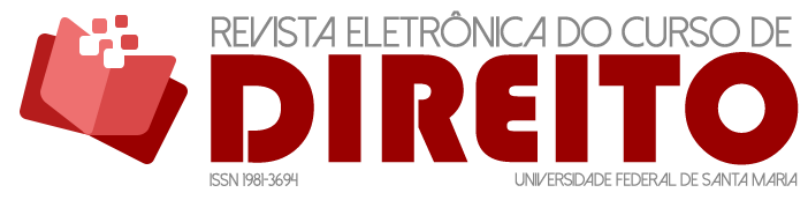

POLÍTICA PÚBLICA, DESENVOLVIMENTISMO NEOEXTRATIVISTA E A COSMOVISÃO INDIGENA: O POLÊMICO PROJETO DA RODOVIA CORTANDO O TIPNIS NA BOLÍVIA

Liton LANES PILAU SOBRINHO CLEIDE CALGARO THIAGO DOS SANTOS DA SILVA

ligar a rodovia transamazônica ao Pacífico, bem como criaria nova rota para os produtores de folhas de coca, grande base de apoio do Presidente Evo Morales.

0 presente artigo, portanto, importa-se em analisar o projeto de rodovia proposto pelo Governo Morales, guiando-se pelo problema de pesquisa que busca responder se a rodovia pelo TIPNIS, nos moldes propostos pelo Governo, oferece risco à manutenção do ambiente equilibrado e da cosmovisão dos povos originários, servindo como política de desenvolvimento neoextrativista?

O objetivo geral do trabalho evidencia-se em analisar, de forma crítica, as antinomias entre o projeto de construção de uma rodovia por dentro de um parque ecológico e território indígena e a cosmovisão dos povos originários que ocupam esse espaço. Como objetivos específicos, cada um relacionado a um item do trabalho, definiu-se abordar os aspectos históricos, geográficos, biofísicos e socioeconômicos do TIPNIS; evidenciar as diferentes observações da relação com o ambiente entre a cosmovisão indígena e o neoextrativismo desenvolvimentista; e, por fim, explorar o projeto de construção de uma rodovia pelo TIPNIS e as manifestações populares contrárias ao projeto, bem como suas perspectivas. 0 método utilizado para o estudo é o analítico dedutivo.

0 presente trabalho, portanto, está dividido em três itens, sendo que o primeiro se importará em apresentar ao leitor o Território Indígena e Parque Nacional Isibóro Sécure TIPNIS, desde seus precedentes históricos, mas, principalmente, dados sobre sua geografia, questões biofísicas e os grupos sociais que ocupam esse espaço. 0 segundo item preocupa-se em evidenciar as disparidades nas formas de observação do mundo entre os indígenas originários e os colonos produtores de folhas de coca, que ocupam o TIPNIS, que representam, de um lado, uma relação de buen vivir com o ambiente e, de outro, uma ideia de exploração dos espaços ambientais.

Já o terceiro item, como fechamento do presente trabalho, se preocupa em analisar o projeto de rodovia pelo TIPNIS, bem como as manifestações populares, favoráveis e contrárias, ao mesmo. Ademais, como elucidação aos leitores, são trazidos dados retirados de outros projetos semelhantes ao da rodovia objeto do presente trabalho.

Assim, o discurso do presidente Morales, sempre com manifestações de cunho nacionalista e de pós-neoliberalismo, acaba se chocando com algumas práticas que são colocadas em prática em seu governo, que demonstram, em verdade, políticas neoextrativistas, com foco exclusivo no crescimento econômico como modelo de desenvolvimento. 


\section{TERRITÓRIO INDÍGENA E PARQUE NACIONAL ISIBÓRO SÉCURE COMO ÁREA INTANGÍVEL}

O que hoje se denomina TIPNIS, foi criado em 1965, pelo Decreto Lei 07401, como Parque Nacional Isibóro Sécure, com menor área que a atual, sendo limitado o Parque pelos rios Isibóro e Sécure. Ou seja, já nos anos 1960 havia uma ideia de reduzir a intervenção humana em espaços de floresta amazônica.

Durante o final dos anos 1980 e início dos anos 1990, havia claro descompasso entre as políticas promovidas pelo Governo e os interesses da população boliviana. Nesse cenário, em setembro de 1990, os povos indígenas do Beni realizaram uma marcha até a capital boliviana, La Paz, como forma de demonstrar seu descontentamento com as políticas liberais do governo. A chamada Gran Marcha por el Territorio y la Dignidad ${ }^{1}$, foi um marco político-social na Bolívia, tendo, inclusive, apoio do, à época, líder dos cocaleros Evo Morales.

Diante da manifestação social promovida pelos grupos indígenas das "terras baixas" bolivianas, o presente Jaime Paz Zamora firmou o Decreto Supremo 22610², em 24 de setembro de 1990, reconhecendo o Parque Nacional como território indígenas dos povos Moxeño, Yuracaré y Chimán, denominando-o, então, Território Indígena e Parque Nacional Isibóro Sécure, ampliando sua área para incorporar as comunidades ribeirinhas, reconhecendo, ainda, os assentamentos colonos existentes na parte sul do Parque, estabelecendo uma chamada linha vermelha limitando tais comunidades.

Em 1997, a Resolução Administrativa do Instituto Nacional de Reforma Agrária emitiu o Título TCO-NAL 000002, consolidando o TIPNIS como Terra Comunitária de Origem (TCO), outorgando a gestão à Subcentral do TIPNIS, órgão local criado como representante dos povos originários habitantes da região do Parque. É preciso destacar, ainda, que a Constituição boliviana de 2009 converteu algumas Terras Comunitárias de Origem, caso do TIPNIS, em Território Indígenas Originários Campesinos, espaços com autonomia indígena originária

\footnotetext{
1 Um dos pontos altos das manifestações dos povos originários bolivianos, ocorridos durante grande parte dos anos 1980 e 1990, foi a Gran Marcha por el Territorio y la Dignidad, iniciada em agosto de 1990, onde mais de 300 homens e mulheres indígenas saíram de Trinidad, no departamento do Beni, e percorreram $640 \mathrm{~km}$, durante 34 dias, até a capital La Paz, na busca de reconhecimento de deus direitos sobre a terra em que viviam e estava sendo desmatada pela indústria madeireira, com anuência do Governo. Ver mais em: <https://www.urgentebo.com/noticia/27-a\%C3\%B1os-de-la-marcha-por-el-territorio-y-la-dignidad-lalucha-contin\%C3\%BAa>. Acesso em 02 fev. 2018.

2 BOLÍVIA. Decreto Supremo $N^{\circ}$ 22610. Disponível em: https://www.lexivox.org/norms/BO-DS22610.xhtml. Acesso em 02 fev. 2018.
} 
ISSN 1981-3694

(DOI): $10.5902 / 1981369438606$

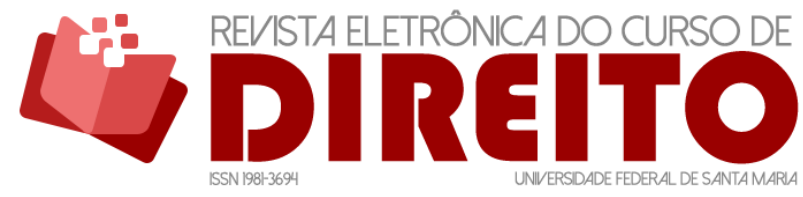

POLÍTICA PÚBLICA, DESENVOLVIMENTISMO NEOEXTRATIVISTA E A COSMOVISÃO INDIGENA: O POLÊMICO PROJETO DA RODOVIA CORTANDO O TIPNIS NA BOLÍVIA

Liton LANES PILAU SOBRINHO CLEIDE CALGARO THIAGO DOS SANTOS DA SILVA

campesina, desde administrativa local até jurídica, conforme o Capítulo Sétimo da Constituição ${ }^{3}$.

Já em 2011, por conta do projeto de rodovia ligando Villa Tunari a San Ignacio de Moxos, que será tratada especificamente no terceiro capítulo, o presidente Evo Morales promulgou a Lei de Proteção do Território Indígena e Parque Nacional Isibóro Sécuro, ou Ley 180, declarando o TIPNIS como "patrimônio sociocultural e natural, zona de preservação ecológica, reprodução histórica e habitat dos povos indígenas Chimán, Yuracaré e Moxeño cuja proteção e conservação são de interesse primordial do Estado Plurinacional da Bolívia"4.

A Lei 180, de 2011, reconheceu ao TIPNIS caráter indivisível, imprescritível, inimbargável, inalienável e irreversível como área protegida de interesse nacional, como forma de garantia aos povos originários, habitantes do local, que novos projetos de políticas públicas não afetariam o ambienta do Parque e, especialmente, a cosmovisão dessas comunidades e sua relação com a terra.

O TIPNIS ocupa, atualmente, uma área de cerca de 1.302.757,2 hectares, entre os departamentos de Beni e Cochabamba, na região baixa do Estado Boliviano, sendo que a divisão departamental corta o Parque, conforme Mapa 1, abaixo:

Mapa 1 - Localização Geográfica do TIPNIS

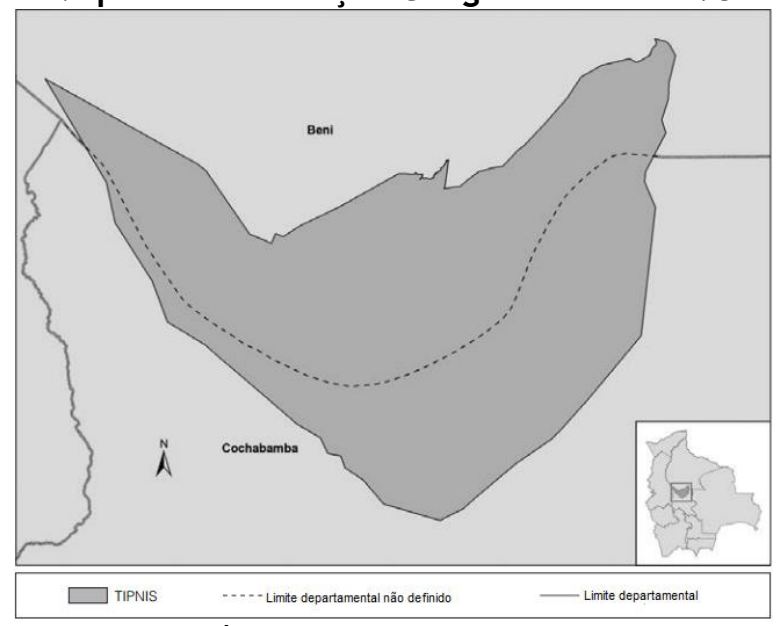

Fonte: Compensación por servicios ambientales de carbono 5 .

3 BOLívIA. Constitución Política del Estado. 2009. Disponível em: https://www.oas.org/dil/esp/Constitucion_Bolivia.pdf. Acesso em 02 fev. 2018.

${ }^{4}$ BOLÍVIA. Ley de protección del territorio indígena y parque nacional Isibóro Sécure - TIPNIS. 2011. Disponível em: http://www.somossur.net/documentos/Ley180corta_TIPNIS24102011.pdf. Acesso em 01 fev. 2018.

${ }^{5}$ RIOS, Maria Teresa Vargas; RIVERO, Noelia Garzón; RICO, Edil Osinaga; MULLER, Robert. Compensación por servicios ambientales de carbono: una alternativa para reducir la deforestación en el TIPNIS. La Paz: Embajada Real de Dinamarca; Fundación PIEB, 2012. 
ISSN 1981-3694

(DOI): $10.5902 / 1981369438606$

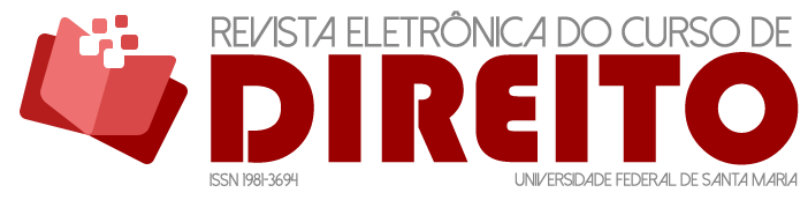

POLÍTICA PÚBLICA, DESENVOLVIMENTISMO NEOEXTRATIVISTA E A COSMOVISÃO INDÍGENA: O POLÊMICO PROJETO DA RODOVIA CORTANDO O TIPNIS NA BOLÍVIA

Liton LANES PILAU SOBRINHO CLEIDE CALGARO THIAGO DOS SANTOS DA SILVA

Além da localização geográfica privilegiada, por estar localizado ao centro do Estado boliviano, nas chamadas terras baixas, em contraste com as terras altas da Cordilheira dos Andes, o TIPNIS é Território Indígenas Originários Campesinos, desde a promulgação da Constituição de 2009 - sendo Terra Comunitária de Origem desde 1997. Os aspectos populacionais e demográficos do TIPNIS são heterogêneos, haja vista que, mesmo sendo território originário indígena, há uma parte, ao sul, colonizada por produtores de coca e, ao leste, por pequenos pecuaristas, todas comunidades interculturais andinas.

Apesar da dificuldade de quantificar a população total que ocupa o TIPNIS, em razão de que algumas comunidades do território estão em isolamento ou de recente contato, o Governo boliviano estima que o TIPNIS seja formado por 64 comunidades, com uma população de mais de 5.000 (cinco mil) habitantes.

Essas 64 comunidades são divididas entre três grandes grupos culturais, os Moxeño - cerca de $68 \%$ do total da população, ocupando a área de encontro entre os rios Isibóro e Sécure, ao leste do Parque, bem como grande parte da faixa central -; os Yuracaré - 26\% da população do Parque, capilarizados em praticamente todo TIPNIS, com exceção da faixa central -; e os Chimán - 4\% do total da população, que historicamente se estabelecem na faixa Norte do Parque, chamada pé do monte, pela proximidade com as terras altas da Cordilheira.

Além dos três grandes grupos culturais, que detêm o título do TIPNIS como Terra Comunitária da Origem, há cerca de $2 \%$ que pertencem a outros grupos étnicos, além das comunidades interculturais andinas, que não entram na contagem da população originária do Parque. Desde os anos 1970 e 1980 há um processo de colonização da região sul do TIPNIS, impulsionado pela abertura de vias de acesso próximas, que produziram assentamentos de colonos.

O processo de colonização do TIPNIS se estabilizou nos anos 1990, com o estabelecimento de uma linha vermelha que delimita o avanço dos colonos, embora, pelo Mapa 2, seja possível observar que tais limites estão sendo paulatinamente desrespeitados. Além dos povos originários e dos colonos cocaleros do sul, há uma faixa razoável, ao leste do Parque, ocupada pelos criollos, assim chamados os primeiros brancos nascidos nas terras bolivianas e, posteriormente, com alguma mestiçagem. São pecuaristas que convivem sem maiores atritos com os povos 
ISSN 1981-3694

(DOI): $10.5902 / 1981369438606$

\section{DIREITO}

POLÍTICA PÚBLICA, DESENVOLVIMENTISMO NEOEXTRATIVISTA E A COSMOVISÃO INDIGENA: O POLÊMICO PROJETO DA RODOVIA CORTANDO O TIPNIS NA BOLÍVIA

LITON LANES PILAU SOBRINHO Cleide CALgaro

THIAGO DOS SANTOS DA SILVA

originários, em razão de se estabelecerem em uma área de descampado, ao contrário dos produtores de coca do sul, que, para seu cultivo, demandam a derrubada da mata amazônica6 .

No Mapa 2, é possível observar a distribuição dos povos originários em todas as áreas dos TIPNIS, bem como a instalação das comunidades produtoras da folha de coca, ao sul, e interculturais criollas, ao leste.

\section{Mapa 2}

\section{Áreas ocupadas por diferentes grupos sociais no TIPNIS}
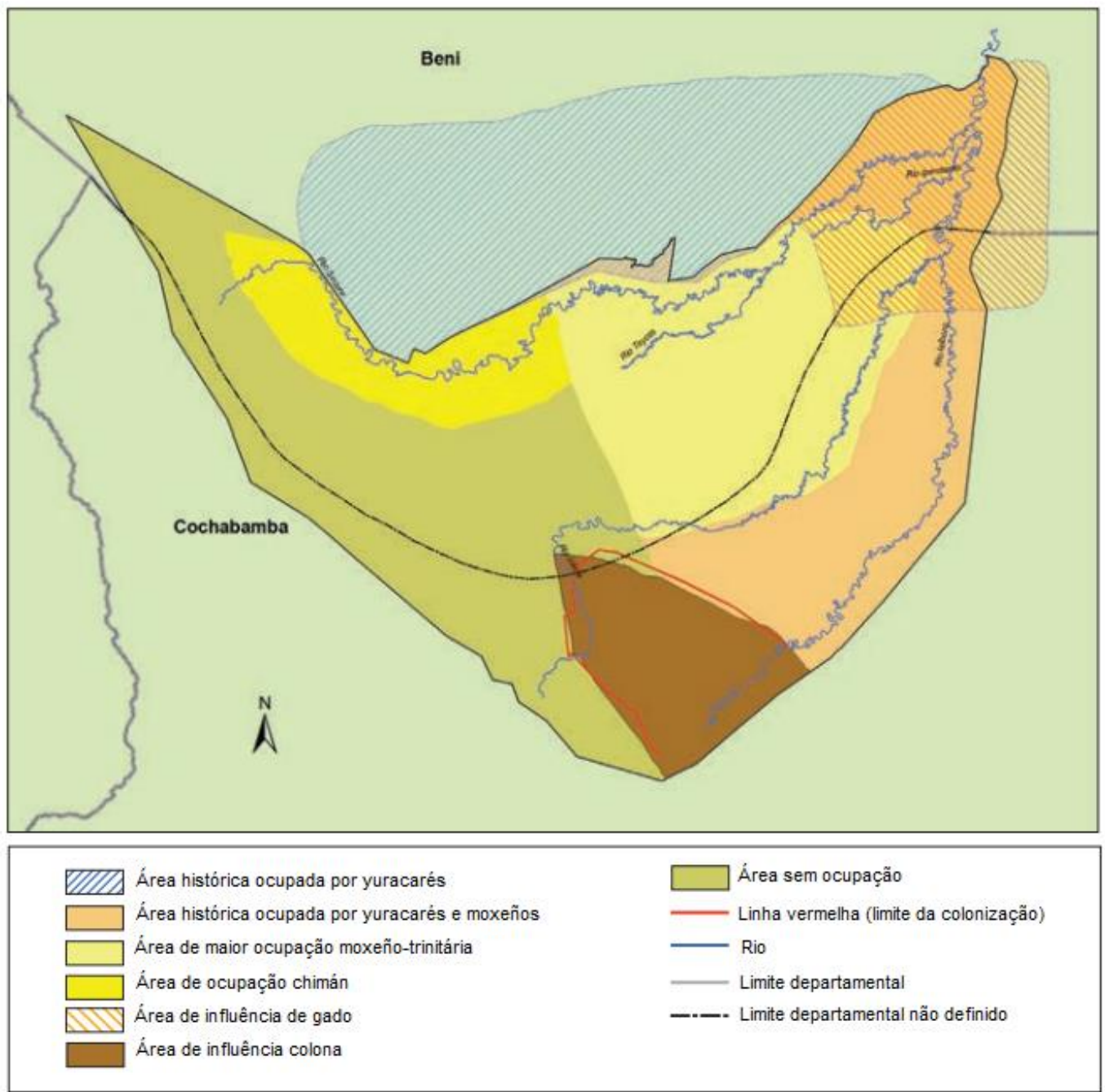

Fonte: Compensación por servicios ambientales de carbono ${ }^{7}$.

\footnotetext{
${ }^{6}$ A questão conflituosa entre colonos cocaleros e os povos originários do TIPNIS, especialmente naquilo que tange à relação entre os grupos e a terra, será abordada com maior afinco no segundo item do presente trabalho.

${ }^{7}$ RIOS, Maria Teresa Vargas; RIVERO, Noelia Garzón; RICO, Edil Osinaga; MULLER, Robert. Compensación por servicios ambientales de carbono: una alternativa para reducir la deforestación en el TIPNIS. La Paz: Embajada Real de Dinamarca; Fundación PIEB, 2012.
} 
Os assentamentos colonos, na parte sul do Parque, já ultrapassam a linha vermelha limite, e acabam “empurrando" as comunidades originárias para o Norte, já que para o cultivo da coca é necessária a derrubada da mata amazônica. Entretanto, o direcionamento dos povos originários para o Norte do Parque é prejudicial às comunidades, em razão dos aspectos biofísicos do TIPNIS.

Segundo o Plano de Gestão do TIPNIS, formulado em 2005, pelo Serviço Nacional de Áreas Protegidas - SERNAP, o Parque apresenta duas áreas climáticas claramente diferenciadas. Uma região de planícies, marcada por sazonalidade e precipitações moderadas, e a região de serras sub-andinas, com tempo predominantemente seco $^{8}$. Em razão das maiores dificuldades climáticas oferecidas pela parte mais ao Norte do TIPNIS, em razão da características subandina, há pouca ocupação desses espaços, como demonstrado no Mapa 2, sendo que o avanço da linha vermelha obriga os indígenas a diminuírem seus espaços originários ou se instalarem em áreas que não lhes são hospitaleiras.

Por conta da fisiogragia do TIPNIS, marcado por muitas áreas elevadas ou próximas da elevação andina, são reduzidos os espaços aptos para agricultura, sendo que grande parte das terras agricultáveis se encontram na linha vermelha, de posse dos produtores de coca.

Porém, o diferencial do TIPNIS, para além de suas características geográficas e físicas, decorre dessa falta de potencialidade agrícola do solo, que se reflete na grande diversidade de ecossistemas e espécies de fauna e flora.

No TIPNIS podem ser observadas quatro formações vegetais (biomas): savana inundável; floresta amazônica sub-andina; floresta amazônica pré-andina e; Yungas9 . Utilizando os dados do Plano de Gestão do TIPNIS, estão registradas 602 espécies de plantas nativas no território do Parque, além de cerca de 2.500 espécies de plantas não exclusivas da floresta amazônica.

Algumas das principais populações de certas espécies são encontradas no TIPNIS, em razão da heterogeneidade paisagística que o Parque apresenta, pelos diferentes biomas que o

\footnotetext{
8 SERNAP. Servicio Nacional de Áreas Protegidas. Plan de Manejo del TIPNIS. 2005. Disponível em: http://sernap.gob.bo/index.php/areas-protegidas/area-natural-de-manejo-integrado/46-areasprotegidas/parque-nacional-y-territorio-indigena/60-isiboro-secure?showall=1\&timitstart=. Acesso em 03 fev. 2018.

${ }^{9}$ Regiões de selva montanhosa que acompanham os Andes. In: SERNAP. Servicio Nacional de Áreas Protegidas. Plan de Manejo del TIPNIS. 2005. Disponível em: http://sernap.gob.bo/index.php/areasprotegidas/area-natural-de-manejo-integrado/46-areas-protegidas/parque-nacional-y-territorioindigena/60-isiboro-secure?showall=1\&limitstart=. Acesso em 03 fev. 2018.
} 
ISSN 1981-3694

(DOI): $10.5902 / 1981369438606$

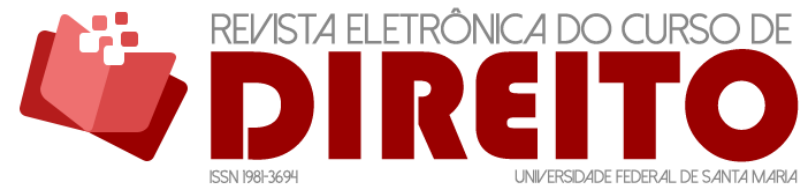

POLÍTICA PÚBLICA, DESENVOLVIMENTISMO NEOEXTRATIVISTA E A COSMOVISÃO INDIGENA: O POLÊMICO PROJETO DA RODOVIA CORTANDO O TIPNIS NA BOLÍVIA

Liton LANES PILAU SOBRINHO CLEIDE CALGARO

THIAGO DOS SANTOS DA SILVA

compõem. É o caso da Swietenia macrophylla ${ }^{10}$, ou Mogno-brasileiro, endêmica da América Latina, e que na Bolívia se encontra com preponderância no TIPNIS. Com isso, o Território Indígena e Parque Nacional Isibóro Sécure é uma das áreas protegidas com maior diversidade florestal da Bolívia ${ }^{11}$, o que se observa do mapa abaixo:

\section{Mapa 3}

Vegetação do TIPNIS.

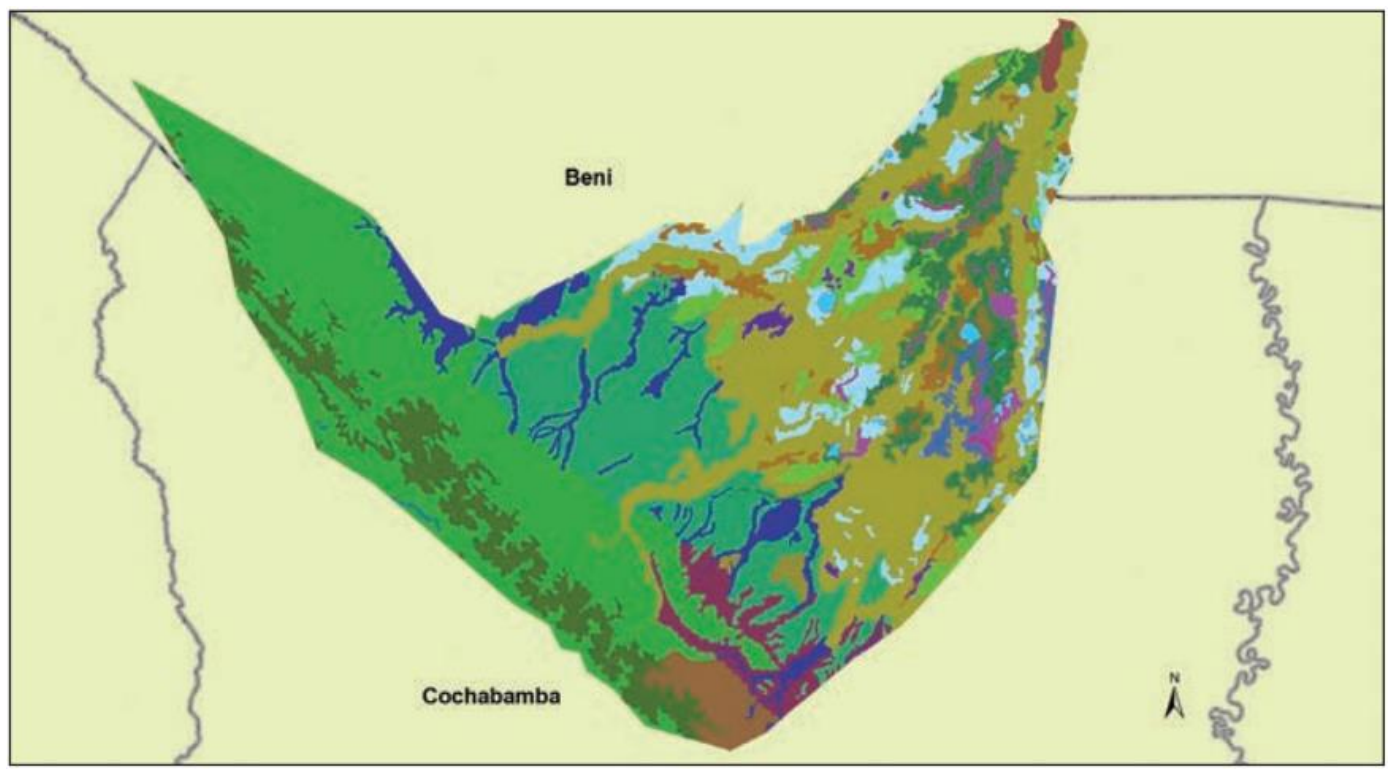

Fonte: Compensación por servicios ambientales de carbono ${ }^{12}$.

O TIPNIS representa um espaço de origem de diversas comunidades, bem como área com presença de diferentes biomas, o que transforma o Parque em local de necessária conservação e não desmatamento. Em razão da ocorrência de espécies endêmicas de fauna e flora, bem como da presença de Povos Originários, há grande potencialidade de desenvolvimento de ecoturismo no Parque.

10 EMBRAPA. Conhecendo espécies de plantas da Amazônia: mogno (Swietenia macrophylla KingMeliaceae). Disponível em: https://www.embrapa.br/busca-de-publicacoes//publicacao/1024143/conhecendo-especies-de-plantas-da-amazonia-mogno-swietenia-macrophylla-king-meliaceae. Acesso em 03 fev. 2018.

${ }^{11}$ RIOS, Maria Teresa Vargas; RIVERO, Noelia Garzón; RICO, Edil Osinaga; MULLER, Robert. Compensación por servicios ambientales de carbono: una alternativa para reducir la deforestación en el TIPNIS. La Paz: Embajada Real de Dinamarca; Fundación PIEB, 2012, p.59.

12 RIOS, Maria Teresa Vargas; RIVERO, Noelia Garzón; RICO, Edil Osinaga; MULLER, Robert. Compensación por servicios ambientales de carbono: una alternativa para reducir la deforestación en el TIPNIS. La Paz: Embajada Real de Dinamarca; Fundación PIEB, 2012. 
ISSN 1981-3694

(DOI): $10.5902 / 1981369438606$

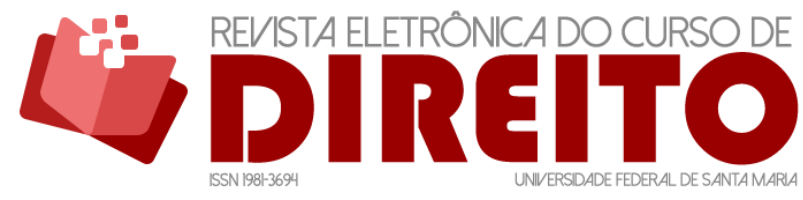

POLÍTICA PÚBLICA, DESENVOLVIMENTISMO NEOEXTRATIVISTA E A COSMOVISÃO INDIGENA: O POLÊMICO PROJETO DA RODOVIA CORTANDO O TIPNIS NA BOLÍVIA

Liton LANES PILAU SOBRINHO CLEIDE CALGARO THIAGO DOS SANTOS DA SILVA

Ainda que nas partes altas do Parque, o custo seja alto, nas partes baixas e, especialmente, nas áreas de nascentes dos rios que dão nome ao espaço. Em entrevista concedida em 2010, Vladimir Orsolini, Diretor do SERNAP, destacava a possibilidade do turismo ecológico no Parque como forma de ingresso de valores, compensando a gestão florestal realizada no local.

Todavia, não se pode vislumbrar o Parque somente como fonte de renda, haja vista que tal observação afronta a visão que os povos originários guardam da terra. A distância entre as formas de relação do indígena com seus espaços e do colono não originário do Parque é o motivo de conflitos entre tais comunidades.

Inclusive, a motivação para delimitação de uma linha vermelha, segurando o avanço colono em relação ao Parque, deu-se por conta da manutenção do modo de vida e da cosmovisão que os indígenas possuem com sua Pacha Mama (Mãe-Terra).

0 próximo item trata de se aproximar dessa relação discrepante entre o buen vivir indígena, que sustenta um ambiente ecologicamente equilibrado e a relação de respeito com a terra, e a relação de desenvolvimentismo econômico dos colonos produtores de coca, que mantém relação de dependência da terra, mas de forma extrativista.

\section{COSMOVISÃO INDÍGENA, BUEN VIVIR E AMBIENTE ECOLOGICAMENTE EQUILIBRADO VERSUS DESENVOLVIMENTO NEOEXTRATIVISTA E CRESCIMENTO ECONÔMICO}

Desde os anos 1980 a América Latina tem observado movimentos pós-colonialistas, responsáveis pela implementação de políticas voltadas ao local, arraigadas nas manifestações culturais próprias dos povos originários e da população mestiça que forma a população dos Estados latino-americanos. Uma série de novos textos constitucionais - ou reformas substanciais - reconheceram as manifestações plurais, desde conformações sociais até pluralidade jurídica. Esse movimento de integração intercultural foi denominado de Novo Constitucionalismo LatinoAmericano.

Tal movimento implementou alguns traços característicos do continente, que o diferenciaram das bases do movimento neoconstitucionalista surgido na Europa no segundo pós- 
ISSN 1981-3694

(DOI): $10.5902 / 1981369438606$

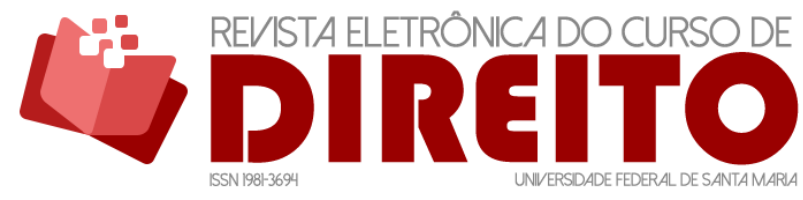

POLÍTICA PÚBLICA, DESENVOLVIMENTISMO NEOEXTRATIVISTA E A COSMOVISÃO INDIGGENA: O POLÊMICO PROJETO DA RODOVIA CORTANDO O TIPNIS NA BOLÍVIA

LITON LANES PILAU SOBRINHO CLEIDE CALGARO

THIAGO DOS SANTOS DA SILVA

guerra, por conta das peculiaridades que a América Latina apresenta, principalmente a mestiçagem e a convivência aproximada de diferentes aportes culturais. Foram introduzidos mecanismos protetores de direitos fundamentais não apenas individuais, mas comunitários, voltados à afirmação da pluralidade e uma tutela do ambiente baseada na cosmovisão dos povos originários.

A diversidade cultural é tema central desse movimento, em contraponto ao modelo europeizado, que unifica Estado e Nação ${ }^{13}$. Tais Constituições apresentam traços em comum, como a estatização dos recursos naturais, reconhecimento aprofundado dos direitos indígenas e formas de participação popular sobre as tomadas de decisões políticas.

A Constituição boliviana integra o terceiro ciclo desse movimento, ou constitucionalismo plurinacional, com ideal de refundação do Estado, com reconhecimento das raízes milenares dos povos originários que os conformam, e passavam ao largo da fundação republicana colonialista ${ }^{14}$. Quando se fala em refundação do Estado, e pela análise do teor do texto constitucional boliviano, especialmente o Preâmbulo, há referência ao fato de que os fundamentos da Bolívia enquanto Estado foram realinhados, para representar, de forma mais aproximada, as nações que a compõem - há clara manifestação constitucional da Bolívia como Estado plurinacional.

Entre os fundamentos referidos no texto constitucional, o buen vivir, ou vivir bien, é apresentado como modelo de Estado ligado à cosmovisão indígena, capaz de sobrepujar o ideal de desenvolvimento ligado exclusivamente ao crescimento econômico. Ou seja, o buen vivir trata de desconstruir uma separação entre a natureza e o indivíduo, projetando a vida de forma comunitária.

Segundo Eduardo Gudynas, o Buen Vivir não é somente mais um modelo de desenvolvimento alternativo, mas um movimento que coloca em discussão toda a base do desenvolvimento ocidental ${ }^{15}$, ligado a um modelo de acumulação de capital. No território boliviano, marcado por manifestações culturais dotadas de pluralidade, uma alternativa ao desenvolvimentismo colonialista é tomada como movimento popular, especialmente pela

13 Durante a modernidade, a nação permaneceu atrelada ao instituto Estado. O Estado-nação foi o responsável por determinar a identidade dos indivíduos nacionais. Ainda que o mundo moderno seja momento em que exsurge o indivíduo como centro, "as culturas nacionais em que nascemos se constituem em uma das principais fontes de identidade cultural". HALL, Stuart. A identidade cultural na pósmodernidade. Tradução Teresa Tadeu da Silva. Rio de Janeiro: DP\&A, 2006, p. 47.

${ }^{14}$ Ver FAJARDO, Raquel Z. Yrigoyen. El pluralismo jurídico en la historia constitucional latinoamericana: de la sujeción a la descolonización. 2010.

15 GUDYNAS, Eduardo. Buen vivir: un relanzamiento necesario. 2010, p. 2. Disponível em: http://www.sinpermiso.info/printpdf/textos/buen-vivir-un-relanzamiento-necesario. Acesso em 06 fev. 2018. 
ISSN 1981-3694

(DOI): $10.5902 / 1981369438606$

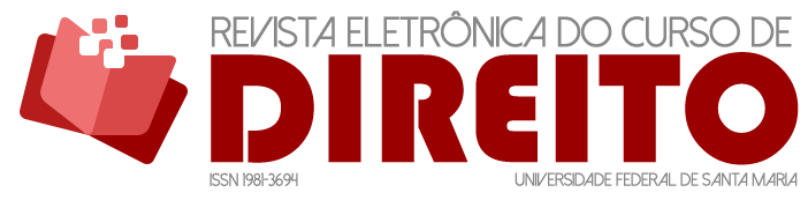

POLÍTICA PÚBLICA, DESENVOLVIMENTISMO NEOEXTRATIVISTA E A COSMOVISÃO INDÍGENA: O POLÊMICO PROJETO DA RODOVIA CORTANDO O TIPNIS NA BOLÍVIA

Liton LANES PILAU SOBRINHO CLEIDE CALGARO

THIAGO DOS SANTOS DA SILVA

afirmação da terra como espaço originário e uma relação de proximidade entre as comunidades e seus territórios.

O desenvolvimentismo clássico se estabelece como modelo de avanço dos países ao final da Segunda Guerra Mundial. Ao final dos anos 1980, início dos anos 1990, com a decorada do comunismo e estabelecimento do capitalismo como modelo econômico global, o ideal de desenvolvimento como aumento econômico é estabelecido como regra. O que se observa é uma transformação do mundo em um modelo homogêneo e universal, em que as vidas são consideradas a partir do mercado e as relações são medidas pelo cosmopolitismo, em uma ideia de cidadania global ${ }^{16}$.

Gudynas compreende que essa homogeneização do modelo de desenvolvimento clássico, ainda que apresentado como ciência, não passou incólume por todos os sociólogos, economistas e cientistas políticos. Isso porque, segundo o autor, "se questionam, por exemplo, a racionalidade do desenvolvimento atual, sua ênfase nos aspectos econômicos e no mercado, sua obsessão com o consumo e o mito de um progresso continuado"17.

Seguindo esse modelo de desenvolvimento clássico, ligado à acumulação de capital, a relação com a terra se torna exclusivamente de apropriação e exploração. Aliás, mesmo os demais sujeitos poderiam ser vistos como objetos disponíveis para o desenvolvimento e progresso humano. Novamente, esse tipo de desenvolvimento confunde crescimento econômico com progresso.

O processo constitucional que refundou o Estado boliviano, intentou implementar, como forma de justificar a refundação alardeada, uma alternativa institucional ao desenvolvimentismo como crescimento econômico, arraigado em um modelo europeu. Com isso, a Constituição de 2009 estabelece o buen vivir (ou vivir bien) - suma qamaña, em quéchua - como um princípio a ser perseguido pelo Estado ${ }^{18}$.

\footnotetext{
${ }^{16}$ Ver DE MARZO, Giuseppe. Buen vivir: para una democracia de la Tierra. La Paz: Plural Editores, 2010.

17 GUDYNAS, Eduardo. Buen vivir: germinando alternativas al desarollo. 2011, p. 02. Disponível em: http://www.ecominga.uqam.ca/PDF/BIBLIOGRAPHIE/GUIDE_LECTURE_1/Gudynas-Buen-vivir-Germinandoalternativas.pdf. Acesso em 06 fev. 2018. Tradução nossa, texto original: "Se cuestionan, por ejemplo, la racionalidad del desarrollo actual, su énfasis en los aspectos económicos y el mercado, su obsesión con el consumo, o el mito de un progreso continuado".

$18 \mathrm{O}$ art. 8.1 da Constituição boliviana faz referência direta ao buen vivir, in verbis: 0 Estado assume e promove como princípios ético-morais de sociedade plural: ama qhilla, ama ilulla, ama suwa (não sejas preguiço, não sejas mentiroso, nem ladrão), suma qamaña (bem-viver), ñandereko (vida em harmonia), teko kavi (vida boa), ivi marael (terra sem mal) e qhapaj ñan (caminho ou vida nobre). BOLIVIA. Constitución Política del Estado. 2009. Disponível na internet em: <https://www.oas.org/dil/esp/Constitucion_Bolivia.pdf>. Acesso em 06 fev. 2018. Tradução nossa, texto original: "El Estado asume y promueve como principios ético-morales de la sociedad plural: ama qhilla,
} 
POLÍTICA PÚBLICA, DESENVOLVIMENTISMO NEOEXTRATIVISTA E A COSMOVISÃO INDIGENA: O POLÊMICO PROJETO DA RODOVIA CORTANDO O TIPNIS NA BOLÍVIA

LITON LANES PILAU SOBRINHO CLEIDE CALGARO

THIAGO DOS SANTOS DA SILVA

O Buen Vivir supõe um ideal de vida e de desenvolvimento que se ligam a partir de uma consciência de utilização da natureza somente no estritamente necessário, evitando possíveis danos ou prejuízo, no intuito de evitar comprometer os direitos das gerações futuras.

[Se trata de] uma visão de conjunto entre indivíduo, comunidade, cultura, natureza, seres vivos, direitos e responsabilidades que acaba em um modelo de desenvolvimento capaz de sustentar e fazer crescer uma economia social e solidária, respeitando os ciclos da vida e, ao mesmo tempo, capaz de fazer emergir, dotando de valor, a independência entre todos os seres vivos ${ }^{19}$.

$\mathrm{Na}$ mesma linha do escritor italiano, mencionado acima, está o uruguaio Eduardo Gudynas, para quem o buen vivir trata de um "espaço onde se abandona a pretensão moderna de dominar e manipular tudo que nos rodeia, sejam pessoas ou a natureza, para convertê-los em meios que sirvam a nossos fins" ${ }^{20}$. Ou seja, o buen vivir serve como local de compartilhamento de diversos elementos que tem um olhar voltado ao futuro.

É preciso que a relação com a natureza seja, também, refundada, porque "os recursos naturais não podem ser vistos como uma condição para o crescimento econômico, tampouco podem ser um simples objeto das políticas de desenvolvimento"21. A humanidade não se retira da natureza para existir, de forma que as políticas públicas, que tenham viés econômico, não podem ser implementadas como se isso fosse possível.

Todos os autores acima comungam da ideia de que é preciso superar a ideia de que a não destruição se equipara ao não aproveitamento. Ou seja, de que há uma relação oposta entre cultura e natureza, de modo que a natureza seja algo externo disponível a ser tomado e aproveitado pela economia. Aí reside a potencial guinada epistemológica que o Buen Vivir

ama llulla, ama suwa (no seas flojo, no seas mentiroso ni seas ladrón), suma qamaña (vivir bien), ñandereko (vida armoniosa), teko kavi (vida buena), ivi maraei (tierra sin mal) y qhapaj ñan (camino o vida noble).

19 DE MARZO, Giuseppe. Buen vivir: para una democracia de la Tierra. La Paz: Plural Editores, 2010, p.164. Tradução nossa, texto original: "una visión de conjunto entre individuo, comunidad, cultura, naturaleza, seres vivos, derechos y responsabilidad que acaba en un modelo de desarrollo capaz de sostener y hacer crecer a una economía social y solidaria, respetuosa de los ciclos de la vida y, al mismo tiempo, capaz de hacer emerger, dotando de valor, a la independencia entre todos los seres vivos".

20 GUDYNAS, Eduardo. Buen vivir: germinando alternativas al desarollo. 2011, p. 02. Disponível na internet em: <http://www.ecominga.uqam.ca/PDF/BIBLIOGRAPHIE/GUIDE_LECTURE_1/Gudynas-Buenvivir-Germinando-alternativas.pdf>. Acesso em $06 \mathrm{fev}$. 2018. Tradução nossa, texto original: "espacio donde se abandona la pretensión moderna de dominar y manipular todo lo que nos rodea, sean personas o la Naturaleza, para convertilo em médios que sirven a nuestros fines".

${ }^{21}$ ACOSTA, Alberto. El buen (con)vivir, una utopía por (re)construir: alcances de la constitución de Montecristi. Obets. Revista de Ciencias Sociales. Vol. 6, n. ${ }^{0} 1$, 2011, pp. 35-67, p. 11. Tradução nossa, texto original: "los recursos naturales no pueden ser vistos como una condición para el crecimiento económico, como tampoco pueden ser un simple objeto de las políticas de desarrollo". 
ISSN 1981-3694

(DOI): $10.5902 / 1981369438606$

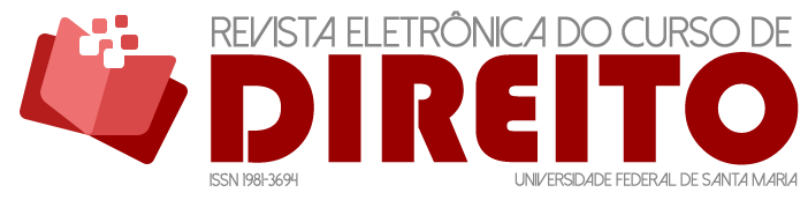

POLÍTICA PÚBLICA, DESENVOLVIMENTISMO NEOEXTRATIVISTA E A COSMOVISÃO INDIGENA: O POLÊMICO PROJETO DA RODOVIA CORTANDO O TIPNIS NA BOLÍVIA

Liton LANES PILAU SOBRINHO CLEIDE CALGARO THIAGO DOS SANTOS DA SILVA

representa, a partir da cosmovisão dos povos originários, propondo o reconhecimento de outras formas de relação com a natureza, que não a de simples ferramenta econômica.

Sob esse viés, o Governo Evo Morales tratou de institucionalizar o discurso do vivir bien, inclusive constitucionalizando-o, no sentido de desconstruir a famigerada equiparação entre crescimento econômico e desenvolvimento nacional. O simples acúmulo de capitais (ou superávit na balança comercial) não pode ser entendido como melhora nas condições de vida da população de um Estado.

O que se observa, contudo, é a ocorrência de algumas contradições entre o discurso institucionalizado e as políticas postas em prática pelo Governo boliviano. 0 caso da rodovia cortando o TIPNIS evidencia, de forma cristalina, essa contradição abissal entre a retórica e as ações tomadas pelo Executivo.

Ocorre, que a base de apoio do presidente Evo Morales é fortemente ligada aos colonos produtores de coca. O próprio Evo é oriundo de comunidades cocaleras, de modo que the foi impossível romper de maneira mais acintosa com o modelo de desenvolvimento clássico, ligado ao extrativismo.

O que se vê no TIPNIS, e que serve como espécie de laboratório, é a discrepância que os modos de vida e produção dos povos originários e os colonos se apresentam. Essa total dissonância se aclara quando da análise dos dados sobre desmatamento da floresta amazônica do Parque

Seja para os povos nativos ou para os colonos assentados, agricultura e pecuária são atividades importantes, enquanto aspecto econômico e de subsistência, no cotidiano do TIPNIS. Todavia, ainda que a produção agrícola e de animais seja algo comum aos ocupantes do Parque, a forma de relação com a terra e o uso dessa produção é o que afasta o agir das comunidades.

Para os povos originários do TIPNIS, agricultura e pecuária, de forma geral, são de subsistência, contudo, com algumas particularidades, variável entre as diferentes nações. Por exemplo, para os Yuracarés, a agricultura tem menor importância, servindo somente às necessidades das comunidades. Em contrapartida, a pecuária (ganadería, em espanhol) tem importância econômica, já que a criação de animais menores, como porcos, permite a comercialização do excedente em mercados externos.

Os Chimán detêm expertise nas práticas de agricultura, é uma nação bastante avançada em relação às práticas de plantio e cultivo de alimentos. A agricultura é de grande importância, pois são uma nação com elevado conhecimento ecológico sobre práticas sustentáveis de utilização da terra, sendo focados na produção de mandioca, abacaxi e cana-de-açúcar. Já a 
ISSN 1981-3694

(DOI): $10.5902 / 1981369438606$

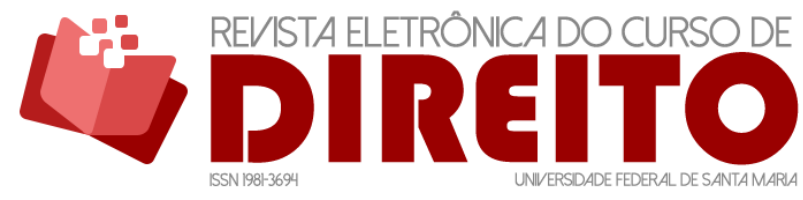

POLÍTICA PÚBLICA, DESENVOLVIMENTISMO NEOEXTRATIVISTA E A COSMOVISÃO INDIGGENA: O POLÊMICO PROJETO DA RODOVIA CORTANDO O TIPNIS NA BOLÍVIA

Liton LANES PILAU SOBRINHO CLEIDE CALGARO THIAGO DOS SANTOS DA SILVA

pecuária não ocupa espaço decisivo na subsistência desses povos, de maneira que criam somente animais menores, exclusivamente para comercialização, pois thes consideram sujos para o consumo 22 .

De outra banda, para os Moxeños, a agricultura possui importância reduzida, sendo de baixo rendimento, pelo pouco conhecimento dessa nação em relação às práticas agrícolas. Todavia, a pecuária tem importância decisiva para essa nação, sendo fonte de intercâmbio comercial para a maioria das famílias, servindo tanto à subsistência como para comercialização do excedente produtivo.

0 que fica claro, pelos dados trazidos pela SERNAP ${ }^{23}$, é que as nações indígenas que ocupam o TIPNIS utilizam-se somente dos recursos necessários. Mesmo a comercialização de excedentes produtivos não tem finalidade de acumulação de capital, mas, somente, de possibilitar o acesso a produtos não produzidos por esses povos. Há uma relação de dependência com a floresta amazônica.

Já para os colonos assentados no sul do Parque, a agricultura é a atividade de maior importância, especialmente arroz, frutas cítricas e coca, esta última a principal produção local, pela rentabilidade que apresenta. Porém, os colonos possuem baixo conhecimento sobre técnicas sustentáveis de produção, fazendo uso de queimadas para utilização da terra, de maneira que esgotam a produtividade local, migrando para outros espaços da floresta para novo desmatamento. Com isso, há pouca disponibilidade de terras e grande concentração (densidade) de produtores, que acabam entrando em conflitos, entre si e com os povos originários, pelo acesso à terra.

Já na parte leste do Parque, há vasta produção pecuária, bastante desenvolvida, realizada pelos assentados criollos. Esses assentamentos de pecuaristas, ocupam a área de confluência dos rios Isibóro e Sécure, se utilizando de serviços dos povos indígenas locais e servindo de espaço intercultural entre os criollos e as nações originárias do Parque. Especialmente nas práticas dos cocaleros, reside a principal razão de conflitos internos ao TIPNIS e de levante das nações localizadas no Parque em relação ao Governo boliviano, por conta de

22 RIOS, Maria Teresa Vargas; RIVERO, Noelia Garzón; RICO, Edil Osinaga; MULLER, Robert. Compensación por servicios ambientales de carbono: una alternativa para reducir la deforestación en el TIPNIS. La Paz: Embajada Real de Dinamarca; Fundación PIEB, 2012, p. 35.

23 SERNAP. Servicio Nacional de Áreas Protegidas. Plan de Manejo del TIPNIS. 2005. Disponível em: http://sernap.gob.bo/index.php/areas-protegidas/area-natural-de-manejo-integrado/46-areasprotegidas/parque-nacional-y-territorio-indigena/60-isiboro-secure?showall=1\&limitstart=. Acesso em 03 fev. 2018 
ISSN 1981-3694

(DOI): $10.5902 / 1981369438606$

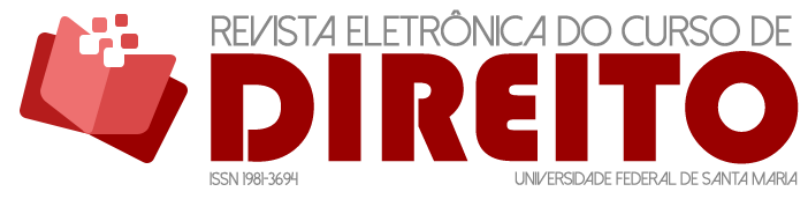

POLÍTICA PÚBLICA, DESENVOLVIMENTISMO NEOEXTRATIVISTA E A COSMOVISÃO INDÍGENA: O POLÊMICO PROJETO DA RODOVIA CORTANDO O TIPNIS NA BOLÍVIA

Liton LANES PILAU SOBRINHO CLEIDE CALGARO THIAGO DOS SANTOS DA SILVA

práticas não-sustentáveis de exploração, como o projeto da rodovia entre Villa Tunari e San Ignacio de Moxos.

O Plano de Manejo do TIPNIS, promovido pela SERNAP, já alertava, em 2005, sobre os processos de desmatamento e sua relação com as práticas dos grupos sociais ocupantes do Parque, especialmente os sistemas de produção e os objetivos econômicos de cada um. Os dados da SERNAP dão conta que as nações originárias do Parque desmatam uma área de 0,5 hectares por família por ano ou a cada dois anos, o que sequer é possível identificar pelo satélite, já que torna possível o recrescimento da Mata Amazônica pelo lento desmatamento.

De maneira contrária, os colonos da zona sul do TIPNIS, nos últimos 30 anos, desmataram mais de $70 \%$ dos 90 mil hectares que ocupam, inclusive superando a linha vermelha estabelecida para segurar seu avanço sobre as áreas virgens do Parque.

O sistema de produção degradante ao ambiente que é implementado pelos colonos cocaleros gera os conflitos entre essas comunidades e as nações indígenas, que observam suas terras serem sobrepostas pela agricultura da folha de coca, bem como já demandaram mudança de seus estilos de vida, pelas diferenças da relação com a terra.

A linha vermelha, definida em 1994 - inclusive com a participação de Evo Morales, à época representante dos colonos -, já foi ultrapassada pelas comunidades presentes no sul do Parque, como é possível observar no Mapa 2. Com isso, as tendências de avanço do desmatamento sobre o TIPNIS são cristalinas, sendo que o projeto de rodovia ligando Villa Tunari a San Ignacio de Moxos é mais um passo na direção do total desmantelamento da Mata Amazônica nessa região, resultado de programas e políticas públicas ligadas a uma ideia de desenvolvimento como crescimento econômico, bem como uma relação de neocolonialismo com o mercado.

O que se pode observar é que o discurso institucional sobre o Buen Vivir como proposta de desenvolvimento não economicista, de respeito à Pacha Mama e de uma relação de estreitamento com a terra permanece no campo da retórica, já que no campo prático, há uma clara adoção de políticas voltadas ao neoextrativismo, ligados a um crescimento econômico pouco sustentável. Um dos projetos mais controversos do Governo Morales é a rodovia projetada para cortar o TIPNIS, sob a justifica de facilitar o acesso aos ocupantes do Parque, mas que gerou uma série de movimentos contrários, assunto do próximo item. 


\section{LA CARRETERA INFAME: A FALÁCIA DO CRESCIMENTO ECONÔMICO COMO DESENVOLVIMENTO}

Eleito em 2005, Evo Morales se tornou o primeiro presidente boliviano de origem indígena, com um discurso nacionalista, contra o colonialismo e as práticas extrativistas pouco sustentáveis. Foi mentor e grande responsável pela reforma constitucional que refundou, em 2009, a Bolívia como Estado Plurinacional, reconhecendo o pluralismo cultural, social, político e jurídico de forma constitucionalmente institucionalizada.

Com esse ideário, e apoiado por setores pouco expressivos na política boliviana, até então, como os povos originários e os produtores de coca, Morales representou uma guinada popular no poder boliviano, oferecendo uma ruptura com o colonialismo que baseava o país sulamericano.

A Constituição de 2009 é um marco jurídico-político estudado em nível internacional, representando uma tendência bastante própria da América Latina, com cartas constitucionais preocupadas em implementar políticas voltadas ao local, com estabelecimento de um olhar multicultural sobre a realidade, com respeito à cosmovisão dos povos originários e garantia de direitos à Pacha Mama, a Mãe-Terra, baseando-se no ideal do Bem-viver como norte do Estado.

Entretanto, mesmo com toda a retórica de reforço das práticas históricas, respeito ao ambiente e à relação entre os povos originários e a Mãe-Terra, a prática das políticas públicas paulatinamente implementadas pelo Governo Morales, e o MAS - Movimiento al Socialismo, demonstram uma dissociação entre as promessas de campanha e a realidade contemporânea. Os críticos de Evo Morales indicam um neocolonialismo, onde se deixou de seguir o ideário eurocêntrico para estabelecer como senhorio o Brasil e a China, aliados políticos de Morales.

Vê-se, portanto, que a chegada ao poder de governos ditos progressistas e as propostas com base no Buen Vivir restavam muito distantes da prática aplicada. Restou inegável a orientação de tais governos a um modelo neoextrativista, que representa pouco, ou quase nenhum, avanço o modelo extrativista clássico precedente ${ }^{24}$.

A conquista do governo por uma rebelião massiva trabalhadora, campesina e popular, que impôs um parlamento de maioria indígena e um presidente uru-aymmara, cuja língua materna é o aymara, não mudou o sistema social imperante no país, sua inserção no

${ }^{24}$ HOLLENDER, Rebecca. Política ambiental de los países "progresistas" en Latinoamerica: Buen vivir vs. Neo extractivismo. ALAI, ago. 2012. Disponível em: http://alainet.org/active/59393\&lang=pt. Acesso em 13 fev. 2018. 
POLÍTICA PÚBLICA, DESENVOLVIMENTISMO NEOEXTRATIVISTA E A COSMOVISÃO INDÍGENA: O POLÊMICO PROJETO DA RODOVIA CORTANDO O TIPNIS NA BOLÍVIA

Liton LANES PILAU SOBRINHO CLEIDE CALGARO

THIAGO DOS SANTOS DA SILVA

mercado capitalista mundial, nem o caráter do Estado. Apesar de todas suas consequências importantes sobre as relações de força entre as classes e os setores sociais - ou seja, sobre o funcionamento do Estado, que é expressão da mesma - não é, sem embargo, mais que um momento em um processo em que todos os dias é preciso conquistas novas mudanças sociais, sob pena de recair no que as mobilizações querem mudar ${ }^{25}$.

O projeto da Carretera Villa Tunari-San Ignacio de Moxos foi um dos ápices da ruptura entre parte da base indígena e o Governo Morales, em razão da dissonância entre o Buen vivir indígena e o neoextrativismo implementado pelo poder central boliviano, como desenvolvimentismo ligado ao simples crescimento econômico.

A rodovia entre Villa Tunari e San Ignacio de Moxos é parte do programa de integração regional entre os departamentos do Beni e Cochabamba, sob a justificativa de melhorar as condições de trocas comerciais entre as regiões, integrando a Ruta F-24, parte da rede nacional de rodovias. Mais do que isso, essa rodovia faz parte da iniciativa para la Integración de la Infraestructura Regional Sudamericana (IIRSA), proposta de integração regional entre os países sul-americanos, com vezes à proporcionar um melhor escoamento das produções do continente ${ }^{26}$.

A despeito do objetivo de redução da pobreza nos países que integram a IIRSA, o crescimento econômico a qualquer custo, como sinônimo de desenvolvimento, se mostra falacioso, especialmente quando há um projeto como o da rodovia cortando o TIPNIS, Parque

${ }^{25}$ ALMEYRA, Guillermo. La Bolívia del TIPNIS: neodesarrollismo extractivista o alternativa al capitalismo. La jornada. Out. 2011. Disponível em: http://www.jornada.unam.mx/2011/10/23/opinion/022a1pol. Acesso em $13 \mathrm{fev}$. 2018. Tradução nossa, texto original: "La conquista del gobierno por una rebelión masiva obrera, campesina y popular, que impone un parlamento de mayoría indígena y un presidente uruaymara cuya lengua materna es el aymara, no cambia el sistema social imperante en el país, su inserción en el mercado capitalista mundial ni el carácter del Estado. A pesar de todas sus consecuencias importantes sobre las relaciones de fuerza entre las clases y los sectores sociales - o sea, sobre el funcionamiento del Estado, que es expresión de la misma - no es, sin embargo, más que un momento en un proceso en el que todos los días hay que conquistar nuevos cambios sociales, so pena de recaer en lo que las movilizaciones quieren cambiar".

${ }^{26}$ Realizada durante as comemorações dos 500 anos de descobrimento do Brasil, entre os dias 31 de agosto de 01 de setembro, em Brasília/DF, a Primeira Reunião de Presidentes Sul-americanos foi palco de um acordo entre os 12 presidentes presentes, com previsão de realização de ações conjuntas para impulsionar o processo de integração política, social e econômica sulamericana, incluindo nas propostas a modernização da infraestrutura regional e ações específicas para fomentar a integração e desenvolvimento de regiões isoladas. Nesse contexto foi lançada a IIRSA - Iniciativa de Integração da Infraestrutura Regional Sul-americana, mecanismo de coordenação de ações intergovernamentais dos doze países signatários, para construção de uma agenda comum para impulsionar projetos de integração de infraestrutura de transportes, energia e comunicações. Primera reunión de presidentes de América del Sur. Disponível em: http://www.iirsa.org/Event/Detail?ld=145. Acesso em 13 fev. 2018. Ver também: Vías para la integración: Ación de la CAF en la infraestructura sostenible de Suramérica. Disponível em: http://www.iirsa.org/admin_iirsa_web/Uploads/Documents/vias_para_la_integracion_2000.pdf. Acesso em 13 fev. 2018. 
ISSN 1981-3694

(DOI): $10.5902 / 1981369438606$

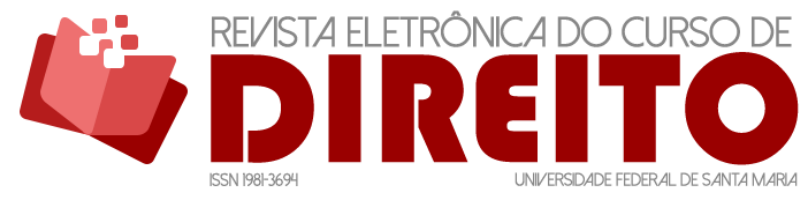

POLÍTICA PÚBLICA, DESENVOLVIMENTISMO NEOEXTRATIVISTA E A COSMOVISÃO INDÍGENA: O POLÊMICO PROJETO DA RODOVIA CORTANDO O TIPNIS NA BOLÍVIA

LiTON LANES PILAU SOBRINHO CLEIDE CALGARO THIAGO DOS SANTOS DA SILVA

Nacional e reserva de Mata Amazônica, garantido como área intangível, além de terra indígena originária. Com um plano de desenvolvimentismo baseado no crescimento econômico, o Governo Morales promulgou, em 2006, a Ley $3.477^{27}$, declarando como prioridade nacional e dos departamentos do Beni e Cochabamba, a elaboração de estudo a desenho final e a construção da rodovia entre Villa Tunari a San Ignacio de Moxos.

A partir de 2008, as obras de desenho e construção da rodovia foram entregues à construtora brasileira OAS, com orçamento de $\$ 415$ milhões de dólares, com $80 \%$ do financiamento pelo BNDES e os $20 \%$ restantes pelo Estado boliviano ${ }^{28}$. A participação da construtora brasileira é tida como obscura pelo ex-ministro de Terras do Governo Morales, Alejandro Almaraz, já que a OAS fora a única participante do processo licitatório, maculado por pouca transparência. Segundo o ex-ministro, a chegada da OAS ao solo boliviano foi definida em "viagem, nos primeiros meses ou semanas do Governo Evo Morales, que fizeram o vicepresidente Álvaro García Linera e Patrícia Ballivián, que nesse instante era diretora administrativa e financeira do Serviço Nacional de Estadas" ${ }^{29}$. Segundo o ex-ministro, houve acordo entre os governos brasileiro e boliviano para facilitação da aterrisagem da OAS na Bolívia $^{30}$.

0 projeto original da rodovia foi dividido em três etapas. 0 primeiro trecho, com $47 \mathrm{~km}$, ligando Villa Tunaria a Inusita; o terceiro trecho, com $82 \mathrm{~km}$, ligando Monte Grande a San Ignacio de Moxos; e o maior trecho, considerado no projeto como segundo, com 117km, ligando Inusita a Monte Grande, previsto para cortar o TIPNIS.

${ }^{27}$ BOLÍVIA. Ley $\mathrm{n}^{\circ}$ 3477, 22 de septiembre de 2006. Disponível em: https://www.lexivox.org/norms/BO-L3477.html. Acesso em 13 fev. 2018.

${ }^{28}$ RIOS, Maria Teresa Vargas; RIVERO, Noelia Garzón; RICO, Edil Osinaga; MULLER, Robert. Compensación por servicios ambientales de carbono: una alternativa para reducir la deforestación en el TIPNIS. La Paz: Embajada Real de Dinamarca; Fundación PIEB, 2012, p. 50.

29 MEDIUM. A mão invisível do BNDES na América Latina. 2015, online. Disponível em: https://medium.com/brio-stories/a-m\%C3\%A3o-invis\%C3\%ADvel-do-bndes-na-am\%C3\%A9rica-latina-

81bfcd8154a9. Acesso em 13 fev. 2018.

30 O BNDES é operado pelo governo brasileiro e tem um programa de crédito específico para a exportação de bens e serviços por parte de companhias do Brasil. Essa rubrica passou a ser utilizada, na última década, como uma plataforma para a internacionalização de empresas brasileiras, especialmente as do setor de construção, como OAS, Odebrecht, Camargo Correa e Andrade Gutierrez. Empresas brasileiras especializadas em infraestrutura se beneficiaram com contratos milionários de obras públicas na América Latina, em grande parte graças aos acordos firmados entre aliados políticos de Luiz Inácio Lula da Silva, presidente do Brasil entre 2003 e 2010. Muitos projetos são bons negócios para as empresas e aumentam o fluxo de dinheiro para o Brasil. MEDIUM, op. cit. 


\section{Mapa 4}

Projeto Inicial de Trajeto da Rodovia

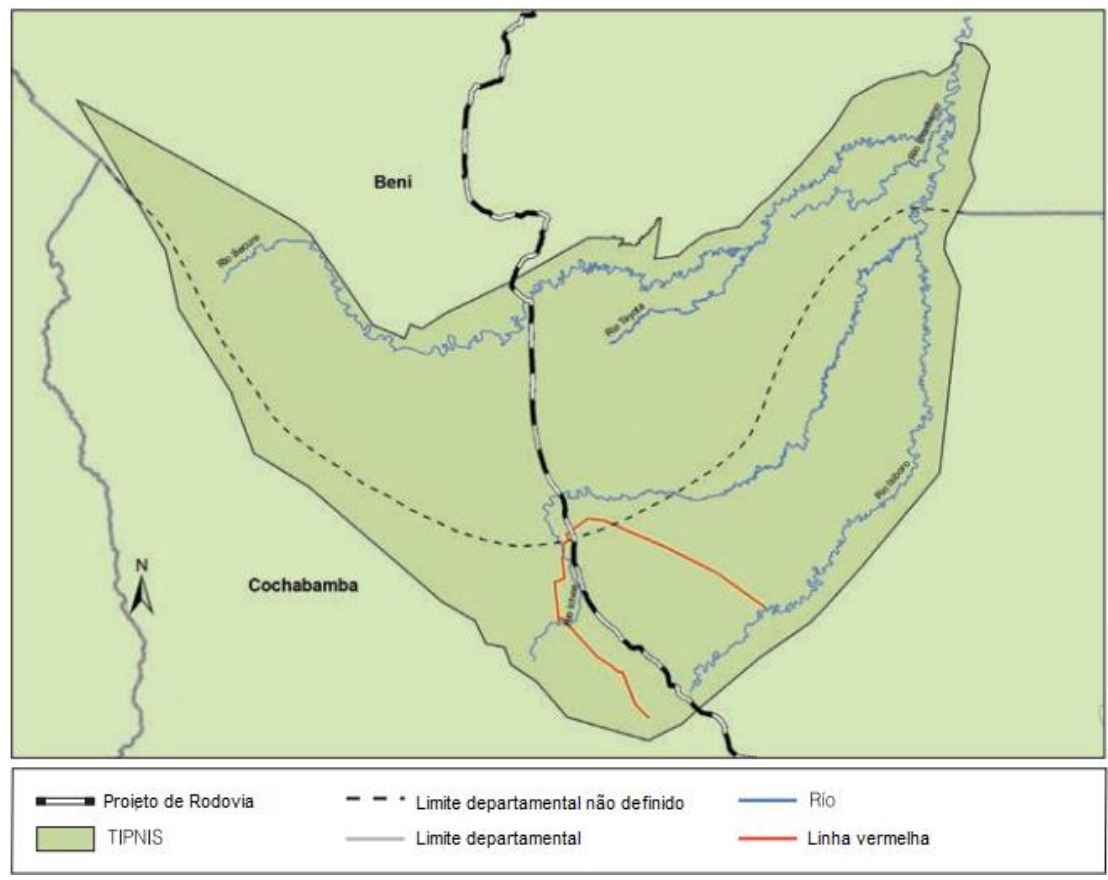

Fonte: Compensación por servicios ambientales de carbono ${ }^{31}$.

Tão logo o projeto foi aprovado pelo Governo boliviano e foram firmados os documentos entre Brasil, Bolívia e BNDES, as manifestações populares foram ruidosas contra a construção de uma rodovia de alta rodagem cortando um Parque Nacional e Território Indígena. A principal manifestação ocorreu em agosto de 2011, quando foi iniciada uma marcha perto da cidade de Trinidad, denominada VIII Marcha Indígena Boliviana, programa para percorrer $596 \mathrm{~km}$, durante 35 dias. Entretanto, o costume indígena de marchar até a sede do Governo para reivindicar suas posições, dessa vez, foi reprimido com certa violência, exatamente quando o Poder é ocupado por um indígena.

Em 25 de setembro, quando alcançavam a cidade de Chaparina, o Governo pressionou os manifestantes com balas de borracha e gás lacrimogênio. Depois disso, colonos apoiadores do Governo trancaram a ponte de Chaparina, impedindo a sequência da marcha e privando o acesso a água e alimentos pelos manifestantes, muitos dos quais com seus filhos no colo. Todavia,

\footnotetext{
${ }^{31}$ RIOS, Maria Teresa Vargas; RIVERO, Noelia Garzón; RICO, Edil Osinaga; MULLER, Robert. Compensación por servicios ambientales de carbono: una alternativa para reducir la deforestación en el TIPNIS. La Paz: Embajada Real de Dinamarca; Fundación PIEB, 2012, p. 51.
} 
POLÍTICA PÚBLICA, DESENVOLVIMENTISMO NEOEXTRATIVISTA E A COSMOVISÃO INDIGGENA: O POLÊMICO PROJETO DA RODOVIA CORTANDO O TIPNIS NA BOLÍVIA

Liton LANES PILAU SOBRINHO CLEIDE CALGARO

THIAGO DOS SANTOS DA SILVA

mesmo com a repressão, os indígenas chegaram em La Paz, com certo atraso, em 19 de outubro, quando foram recebidos pelo presidente Morales $^{32}$.

A principal reivindicação dos indígenas não era a construção da rodovia, mas somente em relação ao trajeto programado e da ausência de consulta prévia aos povos originário, determinação do art. 6.1.a da Convenção 169 da Organização Internacional do Trabalho ${ }^{33}$, firmado pela Bolívia, atingindo a próprio Constituição boliviana, especialmente os artigos $30.11 .15^{34}$ e $343^{35}$.

Um projeto de rodovia cortando um parque ecológico tem potencialidade de destruir o ecossistema ao redor da via, visto que os efeitos ultrapassam, em muito, o trajeto construído, avançando sobre o espaço e atingindo áreas distantes da edificada. Em se tratando do TIPNIS, o risco é ainda maior, já que se trata de um ecossistema com alta biodiversidade, como mencionado no primeiro item, sendo que muitas das espécies de fauna e flora são endêmicas do Parque, além da questão dos povos originários que o ocupam.

Outra insurgência dos indígenas é que a construção da referida rodovia somente trará benefícios aos países limítrofes à Bolívia, especialmente o Brasil, que poderá escoar sua produção diretamente ao Oceano Pacífico em direção à China, e aos colonos produtores de coca

32 MEDIUM. A mão invisível do BNDES na América Latina. 2015, online. Disponível em: https://medium.com/brio-stories/a-m\%C3\%A3o-invis\%C3\%ADvel-do-bndes-na-am\%C3\%A9rica-latina81bfcd8154a9. Acesso em 13 fev. 2018.

33 ORGANIZAÇÃO INTERNACIONAL DO TRABALHO. Convenção $\mathrm{n}^{\circ} 169$ sobre povos indígenas e tribais. 1989. Disponível em: http://portal.iphan.gov.br/uploads/ckfinder/arquivos/Convencao_169_OIT.pdf. Acesso em 13 fev. 2018.

${ }^{34}$ BOLÍVIA. Constitución Política del Estado. 2009. Artículo $30^{\circ}$.- [...] II. No marco da unidade do Estado e de acordo com esta Constituição as nações e povos indígenas originários campesinos gozam dos seguintes direitos: [...] 15. A serem consultados mediante procedimentos apropriados, em particular através de suas instituições, cada vez que se prevejam medidas legislativas ou administrativas suscetíveis de afetar-lhes. Neste marco, se respeitará e garantirá o direito a consulta prévia obrigatória, realizada pelo Estado, de boa-fé, sobre a exploração dos recursos naturais não renováveis no território em que habitam. Tradução nossa, texto original: II. En el marco de la unidad del Estado y de acuerdo con esta Constitución las naciones y pueblos indígena originario campesinos gozan de los siguientes derechos: [...] 15. A ser consultados mediante procedimientos apropiados, y en particular a través de sus instituciones, cada vez que se prevean medidas legislativas o administrativas susceptibles de afectarles. En este marco, se respetará y garantizará el derecho a la consulta previa obligatoria, realizada por el Estado, de buena fe y concertada, respecto a la explotación de los recursos naturales no renovables en el territorio que habitan".

${ }^{35}$ BOLÍVIA, op. cit. Artículo $343^{\circ}$.- A população tem direito a participação na gestão ambiental, a ser consultado e informado previamente sobre decisões que possam afetar a qualidade do meio ambiente. Tradução nossa, texto original: "La población tiene derecho a la participación en la gestión ambiental, a ser consultado e informado previamente sobre decisiones que pudieran afectar a la calidad del medio ambiente". 
ISSN 1981-3694

(DOI): $10.5902 / 1981369438606$

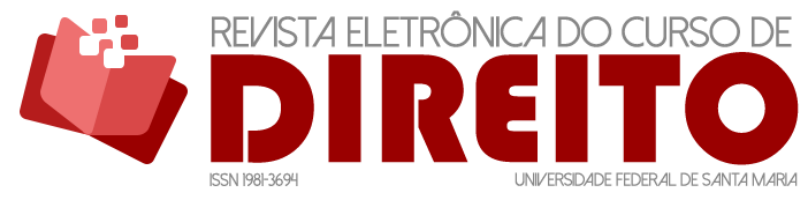

POLÍTICA PÚBLICA, DESENVOLVIMENTISMO NEOEXTRATIVISTA E A COSMOVISÃO INDIGGENA: O POLÊMICO PROJETO DA RODOVIA CORTANDO O TIPNIS NA BOLÍVIA

LITON LANES PILAU SOBRINHO CLEIDE CALGARO THIAGO DOS SANTOS DA SILVA

e extratores de madeira. Ou seja, a justificativa de desenvolvimento local, que permeia o projeto, é apenas tangencial em relação aos verdadeiros beneficiários da obra.

Há uma série de estudos empíricos demonstrando a relação entre rodovias e desmatamento em uma série de países que se utilizaram desse expediente sob a justificativa de desenvolvimento local. Um dos locais que foram estudados por María Amelia Viteri ${ }^{36}$ é o do Brasil, onde rodovias foram implementadas com intuito de oferecer maior acesso a regiões pouco desenvolvidas, entretanto, serviram para valorizar as propriedades para usos não florestais.

O desmatamento em áreas adjacentes às rodovias construídas é um padrão em todo o mundo. Especialmente na Amazônia brasileira, estudos comprovam que até 2020 há uma previsão otimista de perda de $28 \%$ de toda a mata nativa, e em um cenário pessimista essa porcentagem pode subir para $42 \%$ da mata nativa atingida pela construção de rodovias ${ }^{37}$.

Estudos conservadores mensuram que o desmatamento atinge cerca de $2 \mathrm{~km}$ a $3 \mathrm{~km}$ em cada lado das rodovias, porém, há casos de $15 \mathrm{~km}$ de alcance do desmatamento. Na Amazônia brasileira os dados são mais desanimadores, já que os impactos indiretos da construção das rodovias cortando a Amazônia chegam a $50 \mathrm{~km}$ de distância em ambos os lados da rodovia. Segundo Diógenes Alves, na Amazônia brasileira o desmatamento alcançou entre 33\% e 55\% da faixa da $50 \mathrm{~km}$ em ambos os lados das rodovias ${ }^{38}$.

\footnotetext{
36 VITERI, María Amelia. Diagnóstico de la fragilidad de ecosistemas de bosque nativo con criterio ambiental. Chile Florestal, n. 258, 1998, p. 20-21. Disponível em: http://biblioteca.infor.cl/index.asp?param=0\%AD\%88\%92bh\%97\%8Fo\%5D\&Op=12. Acesso em 14 fev. 2018. ${ }^{37}$ RIOS, Maria Teresa Vargas; RIVERO, Noelia Garzón; RICO, Edil Osinaga; MULLER, Robert. Compensación por servicios ambientales de carbono: una alternativa para reducir la deforestación en el TIPNIS. La Paz: Embajada Real de Dinamarca; Fundación PIEB, 2012, p. 44. Ver também: PFAFF, Alexander S. P. What drives deforestation in the Brazilian Amazon? Journal of environmental economics and management. 37.1999, $\quad$ p. $26-43$. 2 Dispinível https://pdfs.semanticscholar.org/6697/3780c1973191abe781737f2c1dee36b002d7.pdf. Acesso em 14 fev. 2018.

${ }^{38}$ ALVES, Diógenes S. An analysis of the geographical patterns of deforestation in Brazilian Amazônia in the 1991-1996 period. University Presses of Florida, 2001, p. 95-111. Disponivel em: https://www.researchgate.net/publication/247152468_An_analysis_of_the_geographical_patterns_of_def orestation_in_Brazilian_Amazonia_in_the_1991-1996_period. Acesso em $14 \mathrm{fev} .2018$.
} 
Imagem de satélite do desmatamento em torno de rodovia na Amazônia brasileira

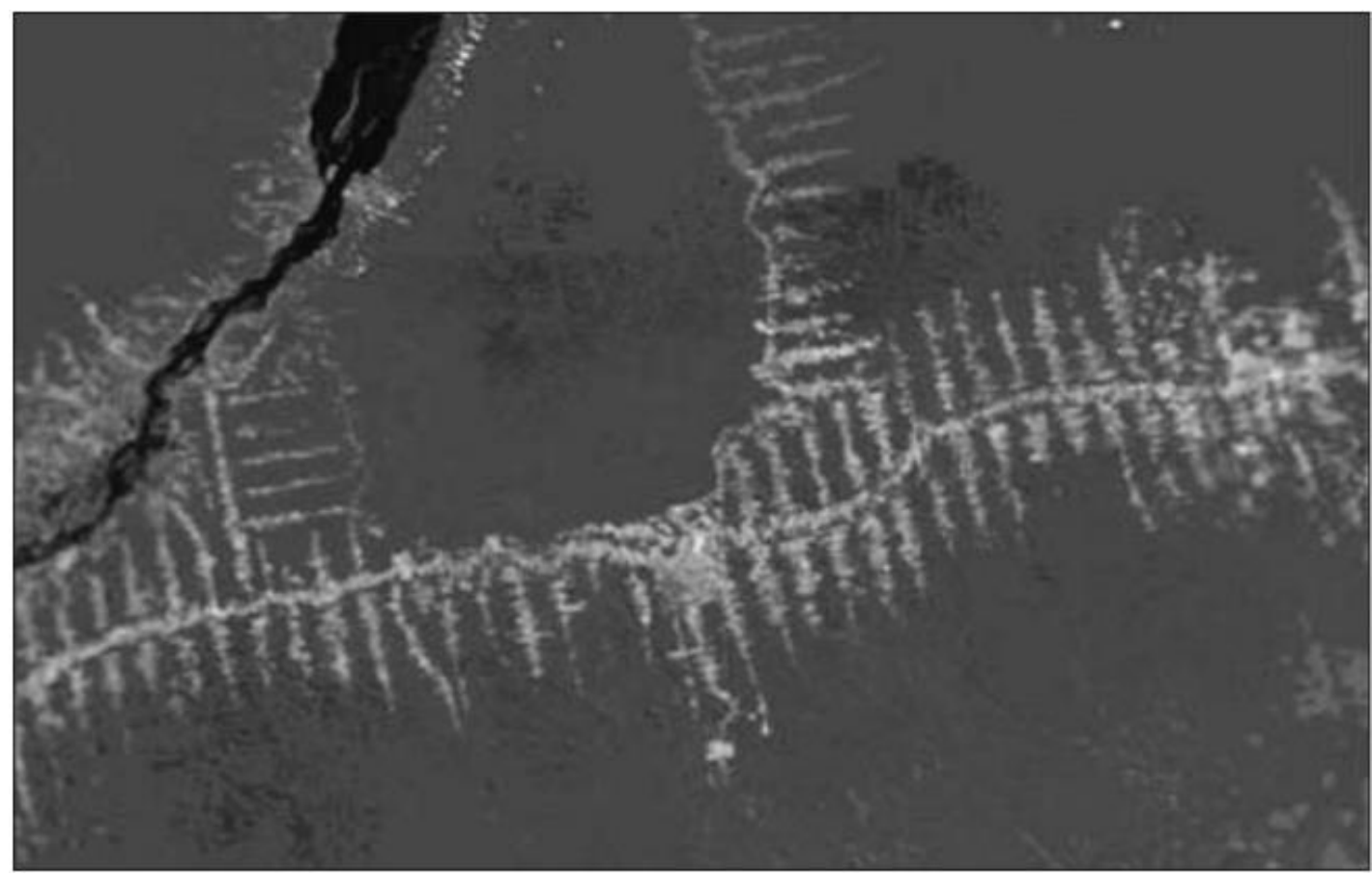

Fonte: Compensación por servicios ambientales de carbono ${ }^{39}$.

Um dos fatores do desmatamento próximo às rodovias construídas em áreas ambientais é o assentamento de pessoas nos arredores das obras. Com as aberturas de rodovias cortando áreas desabitadas, há uma lógica de habitação e instalação de população em todo o trajeto das mesmas, que leva ao desmatamento das áreas próximas para construção de casas e comércios, o que acaba incidindo no surgimento de vilas e, em posterior momento, de cidades completas, elevando a taxa de desmatamento. Especificamente em relação à rodovia projetada para cortar o TIPNIS, foram encomendados estudos que avaliam e tentam prever o nível de desmatamento que será provocado pela obra.

${ }^{39}$ RIOS, Maria Teresa Vargas; RIVERO, Noelia Garzón; RICO, Edil Osinaga; MULLER, Robert. Compensación por servicios ambientales de carbono: una alternativa para reducir la deforestación en el TIPNIS. La Paz: Embajada Real de Dinamarca; Fundación PIEB, 2012, p. 45. 
ISSN 1981-3694

(DOI): $10.5902 / 1981369438606$

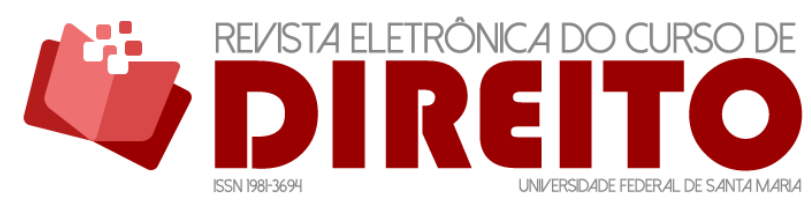

POLÍTICA PÚBLICA, DESENVOLVIMENTISMO NEOEXTRATIVISTA E A COSMOVISÃO INDIGENA: O POLÊMICO PROJETO DA RODOVIA CORTANDO O TIPNIS NA BOLÍVIA

Liton LANES PILAU SOBRINHO CLEIDE CALGARO THIAGO DOS SANTOS DA SILVA

O Parque já segue sendo desmatado, principalmente na parte sul, onde os colonos cocaleros estão assentados, razão da criação da linha vermelha. Porém, é preciso que o Governo realize esforços no sentido de garantir que a linha vermelha seja respeitada, sob pena de que o acréscimo no desmatamento do TIPNIS não se estabilize, mesmo sem a rodovia.

Utilizando imagens do satélite Landsat, é possível identificar o nível de desmatamento dentro do TIPNIS, entre os anos de 1976 e 2007, nos mapas abaixo:

\section{Mapa 5}

\section{Desmatamento entre 1976 e 1986 no TIPNIS}

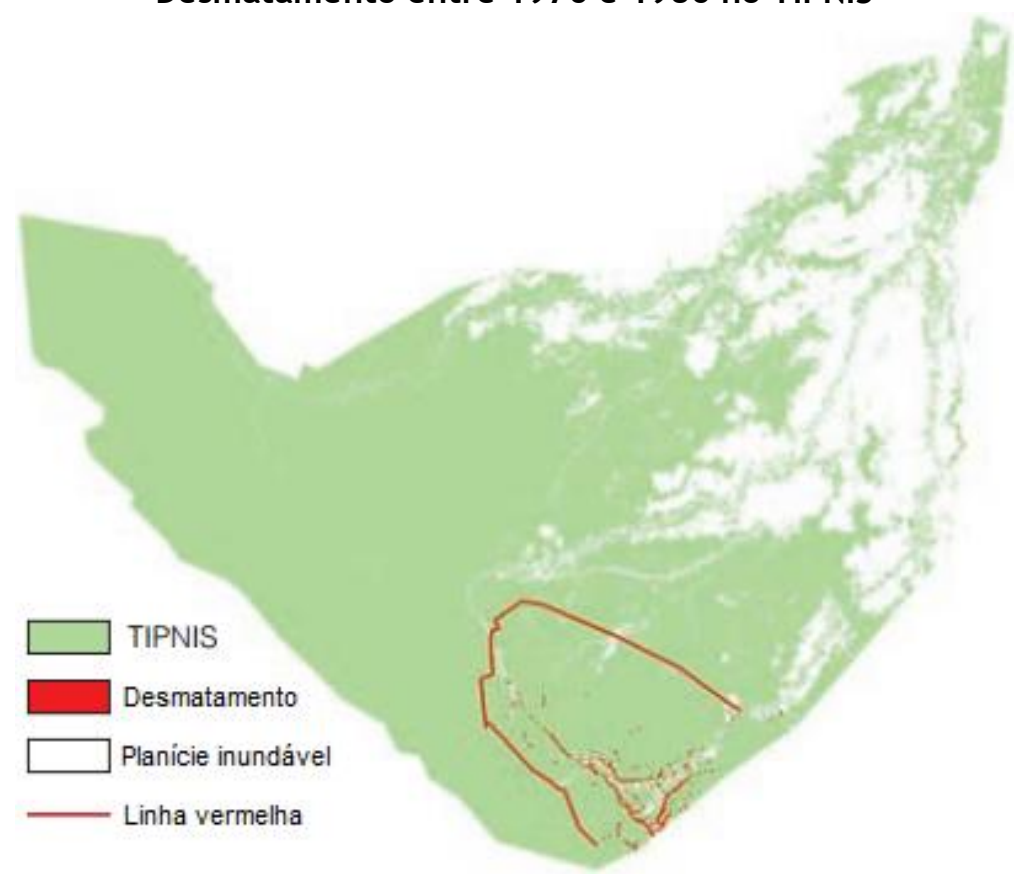

Fonte: Compensación por servicios ambientales de carbono ${ }^{40}$.

\footnotetext{
40 RIOS, Maria Teresa Vargas; RIVERO, Noelia Garzón; RICO, Edil Osinaga; MULLER, Robert. Compensación por servicios ambientales de carbono: una alternativa para reducir la deforestación en el TIPNIS. La Paz: Embajada Real de Dinamarca; Fundación PIEB, 2012, p. 54.
} 
ISSN 1981-3694

(DOI): $10.5902 / 1981369438606$

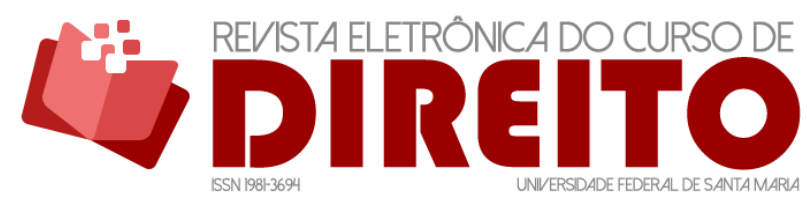

POLÍTICA PÚBLICA, DESENVOLVIMENTISMO NEOEXTRATIVISTA E A COSMOVISÃO INDIGENA: O POLÊMICO PROJETO DA RODOVIA CORTANDO O TIPNIS NA BOLÍVIA

Liton LANES PILAU SOBRINHO

\section{Mapa 6}

Desmatamento entre 1986 e 1991 no TIPNIS

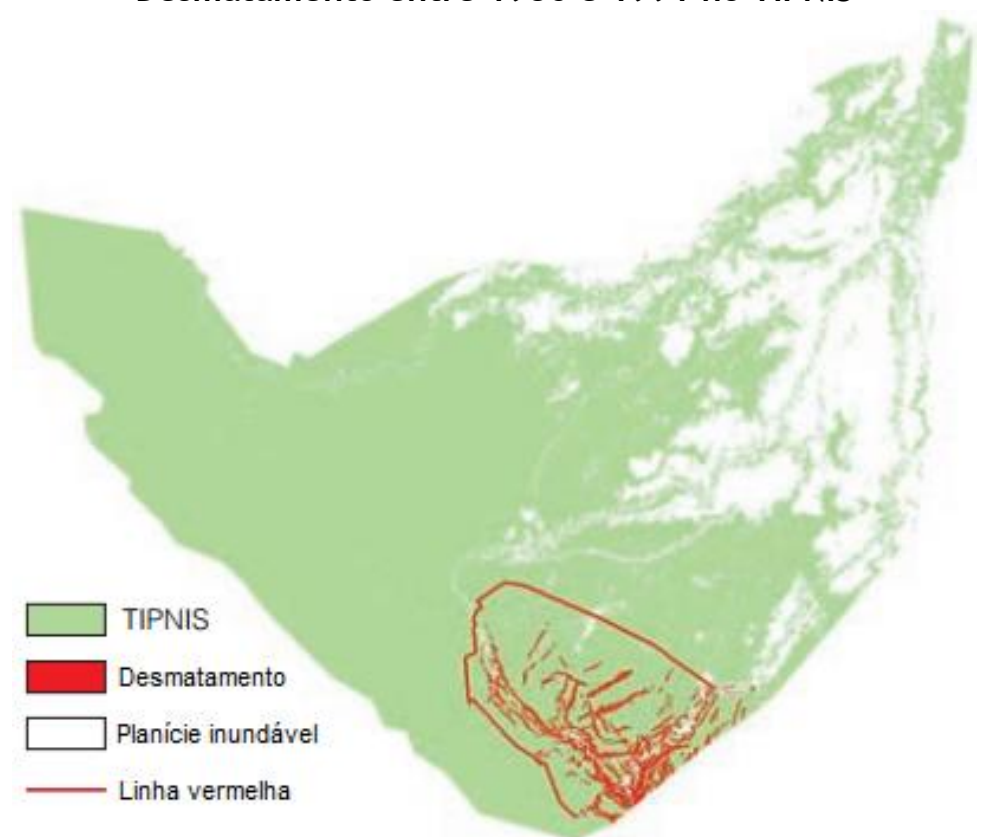

Fonte: Compensación por servicios ambientales de carbono ${ }^{41}$.

Mapa 7

Desmatamento entre 1991 e 2001 no TIPNIS

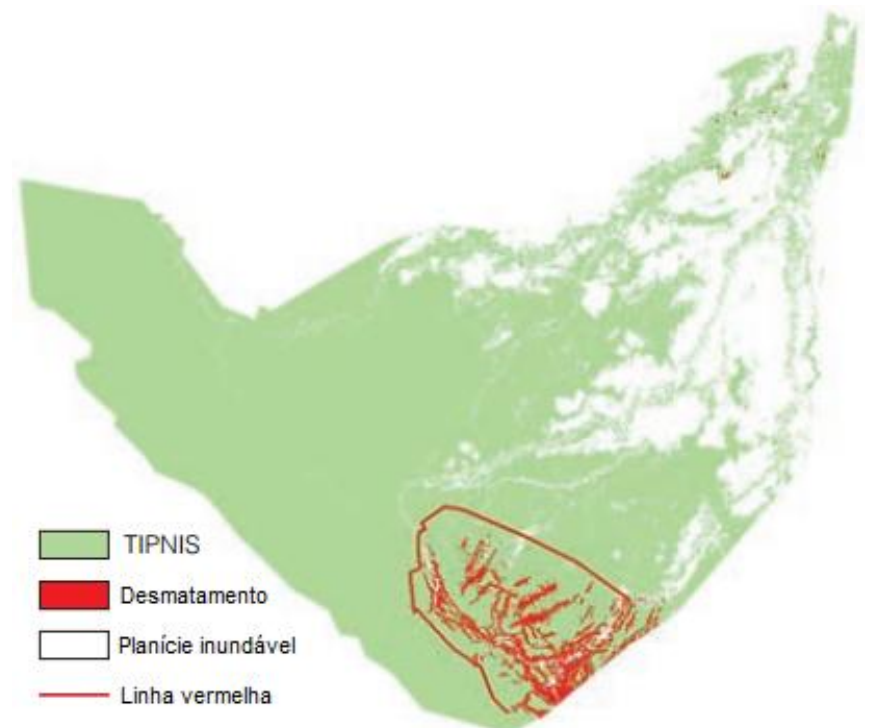

Fonte: Compensación por servicios ambientales de carbono ${ }^{42}$.

\footnotetext{
${ }^{41}$ RIOS, Maria Teresa Vargas; RIVERO, Noelia Garzón; RICO, Edil Osinaga; MULLER, Robert. Compensación por servicios ambientales de carbono: una alternativa para reducir la deforestación en el TIPNIS. La Paz: Embajada Real de Dinamarca; Fundación PIEB, 2012, p. 55.
} 
ISSN 1981-3694

(DOI): $10.5902 / 1981369438606$

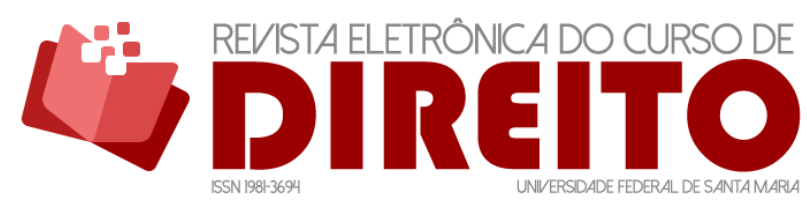

POLÍTICA PÚBLICA, DESENVOLVIMENTISMO NEOEXTRATIVISTA E A COSMOVISÃO INDIGENA: O POLÊMICO PROJETO DA RODOVIA CORTANDO O TIPNIS NA BOLÍVIA

Liton LANES PILAU SOBRINHO Cleide CALgaro THIAGO DOS SANTOS DA SILVA

\section{Mapa 8}

Desmatamento entre 2001 e 2005 no TIPNIS

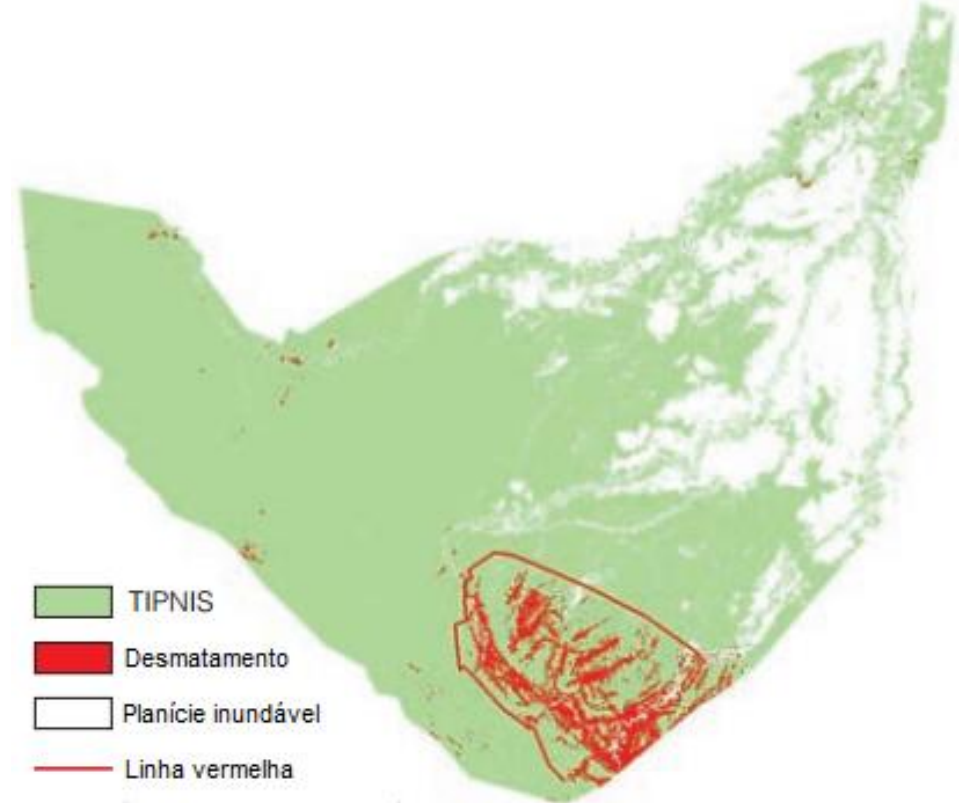

Fonte: Compensación por servicios ambientales de carbono ${ }^{43}$.

\section{Mapa 9}

\section{Desmatamento entre 2005 e 2007 no TIPNIS}

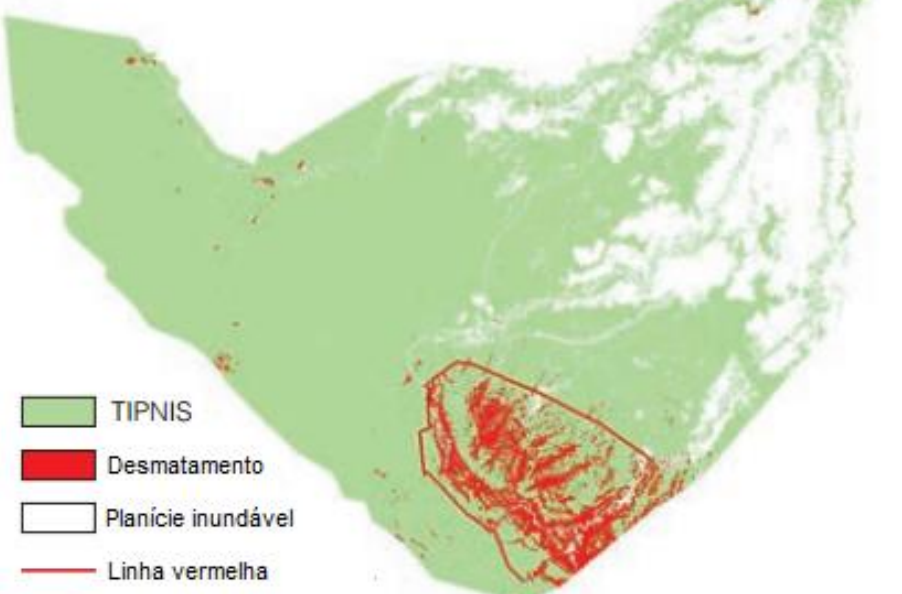

Fonte: Compensación por servicios ambientales de carbono ${ }^{44}$.

\footnotetext{
42 RIOS, Maria Teresa Vargas; RIVERO, Noelia Garzón; RICO, Edil Osinaga; MULLER, Robert. Compensación por servicios ambientales de carbono: una alternativa para reducir la deforestación en el TIPNIS. La Paz: Embajada Real de Dinamarca; Fundación PIEB, 2012, p. 55.

${ }^{43}$ RIOS, Maria Teresa Vargas; RIVERO, Noelia Garzón; RICO, Edil Osinaga; MULLER, Robert. Compensación por servicios ambientales de carbono: una alternativa para reducir la deforestación en el TIPNIS. La Paz: Embajada Real de Dinamarca; Fundación PIEB, 2012, p. 56.
} 
ISSN 1981-3694

(DOI): $10.5902 / 1981369438606$

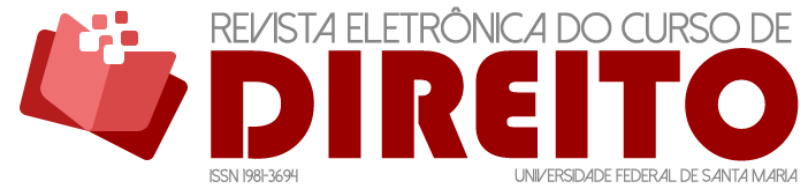

POLÍTICA PÚBLICA, DESENVOLVIMENTISMO NEOEXTRATIVISTA E A COSMOVISÃO INDÍGENA: O POLÊMICO PROJETO DA RODOVIA CORTANDO O TIPNIS NA BOLÍVIA

Liton LANES PILAU SOBRINHO Cleide CALgaro THIAGO DOS SANTOS DA SILVA

Como se observa dos mapas acima, o desmatamento interno à linha vermelha, limítrofe da colonização está com mais de $80 \%$ da área desmatada, isso até o ano de 2007. Ademais, não há total respeito em relação à demarcação, com avanço dos colonos para além da linha vermelha, o que oferece risco aos povos originários.

Com base nos dados obtidos a partir do nível de desmatamento entre 1986 e 2007, espaço de tempo em que houve assentamento dos colonos cocaleros no sul do Parque, são gerados mapas de probabilidade de desmatamento, levando em consideração o avanço da linha vermelha, já que não se identifica respeito total à demarcação, para os próximos 18 anos.

Mapa 10

Probabilidade de desmatamento do TIPNIS em 18 anos sem a rodovia

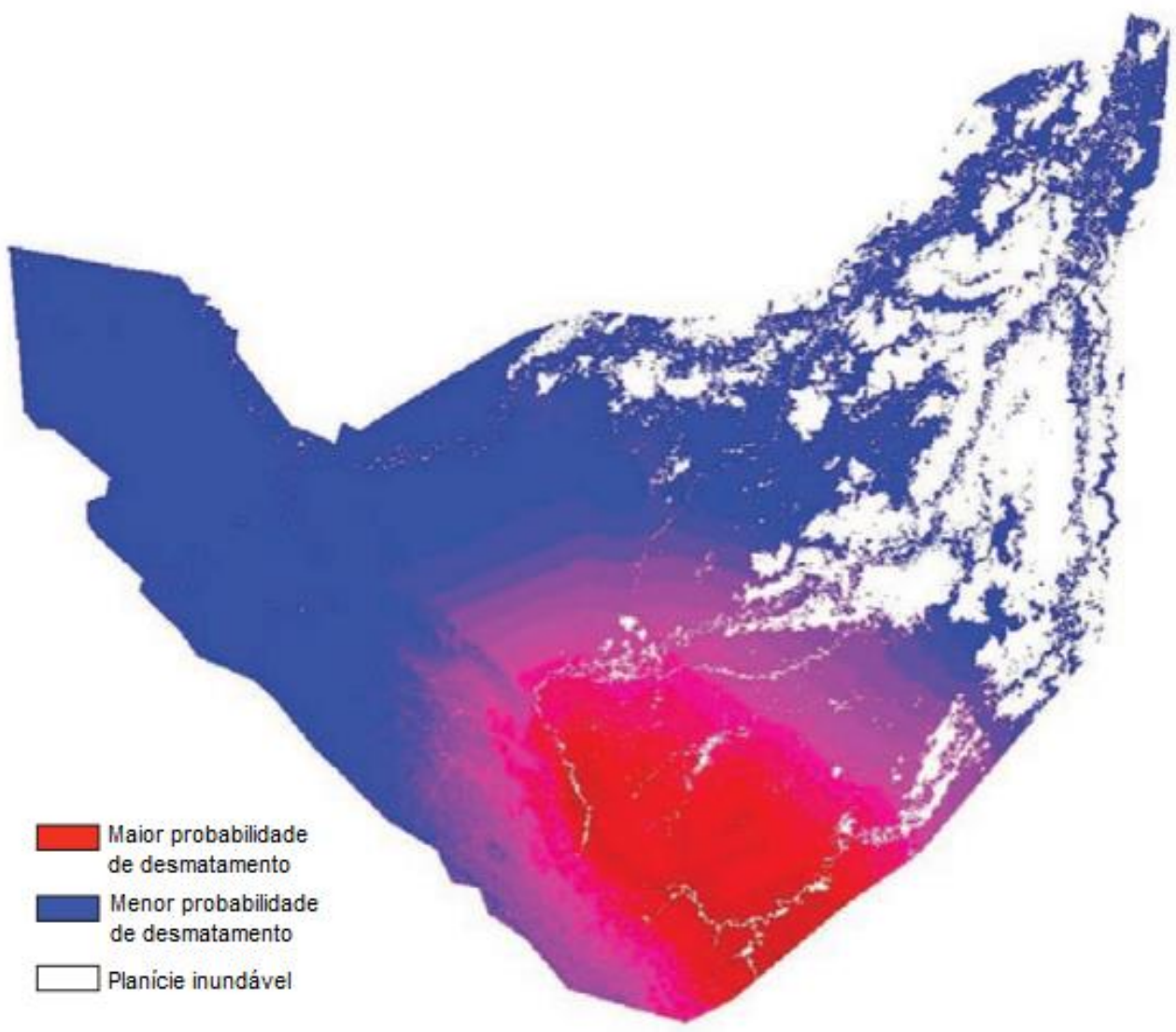

Fonte: Compensación por servicios ambientales de carbono ${ }^{45}$.

\footnotetext{
${ }^{44}$ RIOS, Maria Teresa Vargas; RIVERO, Noelia Garzón; RICO, Edil Osinaga; MULLER, Robert. Compensación por servicios ambientales de carbono: una alternativa para reducir la deforestación en el TIPNIS. La Paz: Embajada Real de Dinamarca; Fundación PIEB, 2012, p. 56.

45 RIOS, Maria Teresa Vargas; RIVERO, Noelia Garzón; RICO, Edil Osinaga; MULLER, Robert. Compensación por servicios ambientales de carbono: una alternativa para reducir la deforestación en el TIPNIS. La Paz: Embajada Real de Dinamarca; Fundación PIEB, 2012, p. 66.
} 
ISSN 1981-3694

(DOI): $10.5902 / 1981369438606$

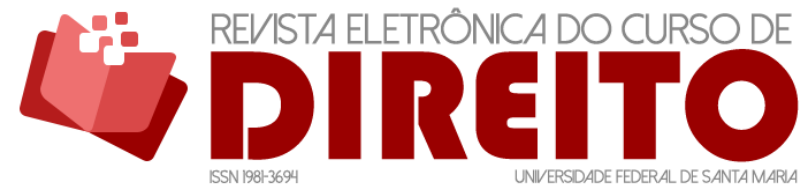

POLÍTICA PÚBLICA, DESENVOLVIMENTISMO NEOEXTRATIVISTA E A COSMOVISÃO INDIGENA: O POLÊMICO PROJETO DA RODOVIA CORTANDO O TIPNIS NA BOLÍVIA

Liton LANES PILAU SOBRINHO Cleide Calgaro THIAGO DOS SANTOS DA SILVA

Sem gestão ambiental dos limites para conter o avanço da colonização, o TIPNIS, mesmo sem a construção da rodovia poderá perder cerca de $43 \%$ de sua área pelo desmatamento causado pelos cocaleros agricultores e pelo comércio de madeira. Caso ocorra a construção da rodovia, as previsões de desmatamento são ainda piores. Isso porque 18 anos após a obra seriam perdidos cerca de 600.000 hectares do Parque, o que equivale a $64,5 \%$ de toda a área do TIPNIS, conforme mapa abaixo.

\section{Mapa 11}

Probabilidade de desmatamento do TIPNIS em 18 anos com a rodovia

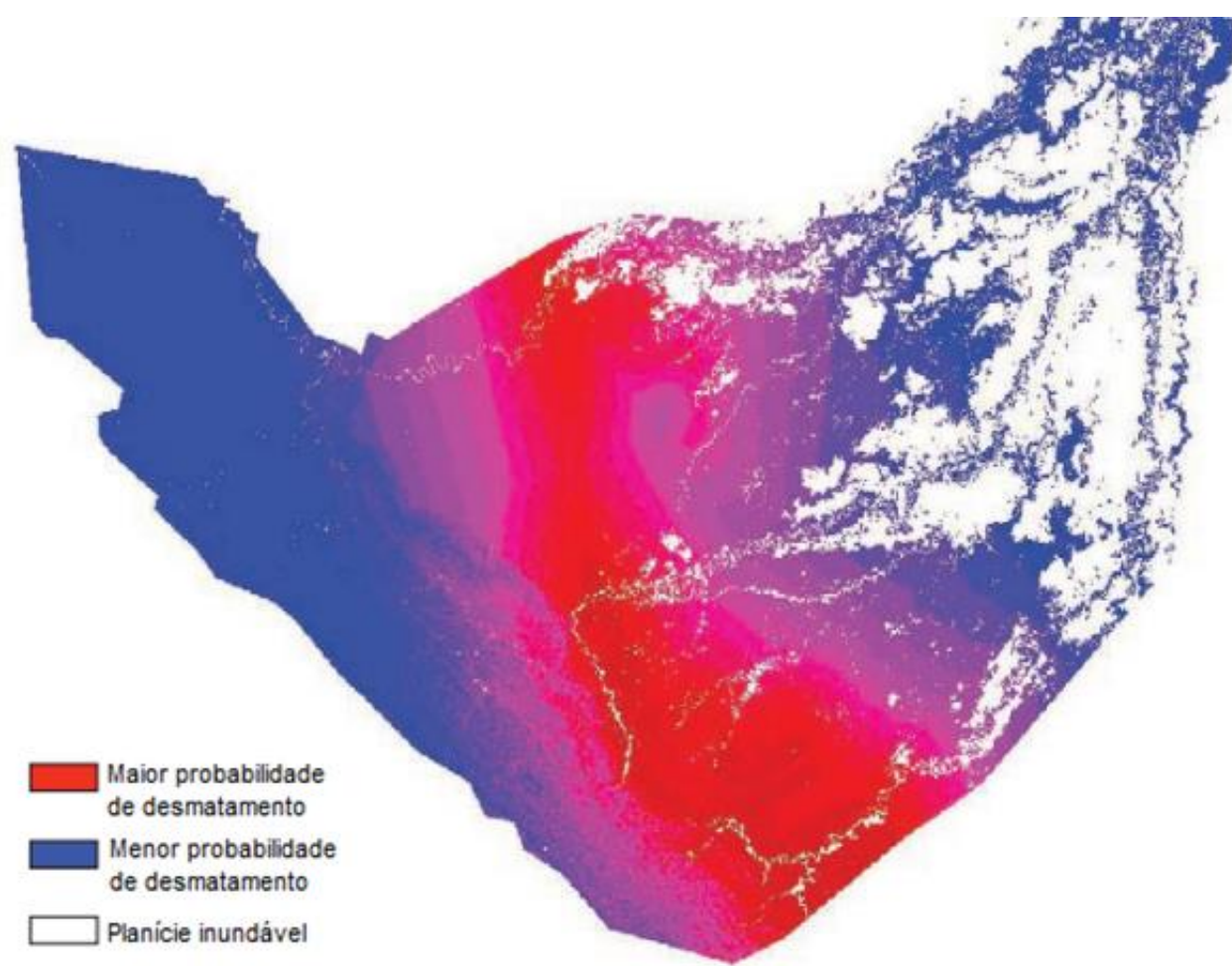

Fonte: Compensación por servicios ambientales de carbono ${ }^{46}$.

Além do desmatamento previsto, em razão da carretera, outro efeito da obra é em relação à total alteração das formas de vida dos povos originários locais, bem como da fauna e flora do Parque. Tal situação ocorre, pois, como os mapas 10 e 11 demonstram, há espaços do

\footnotetext{
46 RIOS, Maria Teresa Vargas; RIVERO, Noelia Garzón; RICO, Edil Osinaga; MULLER, Robert. Compensación por servicios ambientales de carbono: una alternativa para reducir la deforestación en el TIPNIS. La Paz: Embajada Real de Dinamarca; Fundación PIEB, 2012, p. 67.
} 
ISSN 1981-3694

(DOI): $10.5902 / 1981369438606$

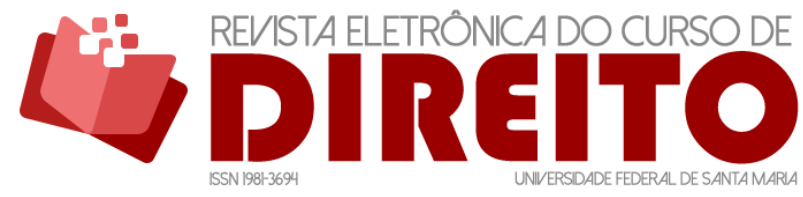

POLÍTICA PÚBLICA, DESENVOLVIMENTISMO NEOEXTRATIVISTA E A COSMOVISÃO INDÍGENA: O POLÊMICO PROJETO DA RODOVIA CORTANDO O TIPNIS NA BOLÍVIA

Liton LANES PILAU SOBRINHO CLEIDE CALGARO THIAGO DOS SANTOS DA SILVA

TIPNIS que permanecem inundados em determinadas épocas do ano e determinam o modus operandi dos ocupantes do Parque.

A construção de uma rodovia, cortando o TIPNIS, obviamente causará alterações razoáveis quanto à área inundável, afetando fauna, flora, bem como os povos originários do Parque. Aliás, mesmo sem a obra da rodovia, como se viu no Mapa 10, é preciso realizar uma gestão sobre o avanço da linha vermelha, visto que os colonos instalados ao Sul do Parque estão avançando sobre tal limite, de maneira que mesmo a inexistência da rodovia oferece previsões pouco otimistas para o TIPNIS.

A imagem abaixo oferece um comparativo entre três previsões possíveis para o TIPNIS, nos próximos 18 anos. No primeiro plano, há previsão do desmatamento no Parque sem a construção da rodovia e com gestão para reduzir o avanço da linha vermelha; no segundo momento, o cenário sem a construção da rodovia, mas também sem gestão ambiental dos limites de colonização, o que acontece no momento; e o terceiro momento é a previsão do desmatamento no TIPNIS após a construção da rodovia.

\section{Imagem 2}

\section{Cenários comparativos de desmatamento no TIPNIS}

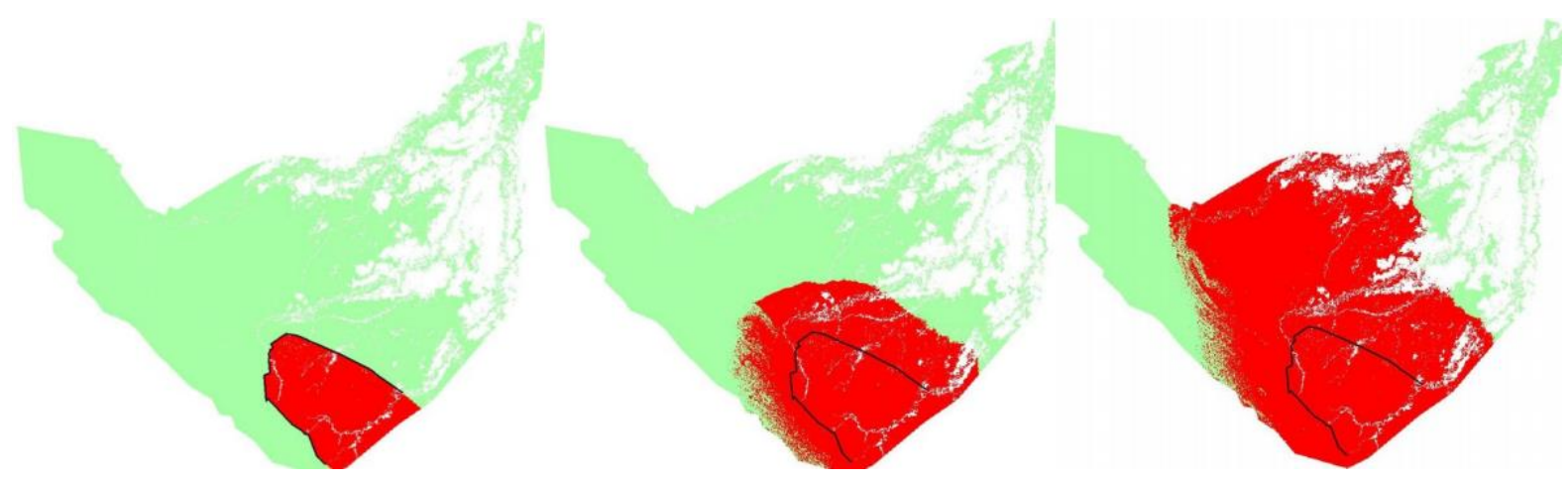

Fonte: Viabilidad económica e institucional para el desarrollo de iniciativas que reduzcan la deforestación en el Territorio Indígena y Parque Nacional Isibóro Sécure ${ }^{47}$.

Todos os estudos técnicos apresentados, corroboraram a marcha promovida pelos povos originários do TIPNIS, estabelecendo-se contrários à construção da rodovia prevista. Com isso,

\footnotetext{
47 PROGRAMA DE INVESTIGACIÓN ESTRATÉGICA EN BOLIVIA. Viabilidad económica e institucional para el desarrollo de iniciativas que reduzcan la deforestación en el Territorio Indígena y Parque Nacional Isibóro Sécure. Disponível em: http://www.pieb.com.bo/sipieb_nota.php?idn=5541. Acesso em $15 \mathrm{fev}$. 2018.
} 
ISSN 1981-3694

(DOI): $10.5902 / 1981369438606$

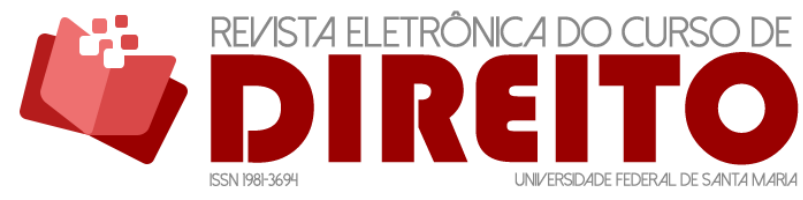

POLÍTICA PÚBLICA, DESENVOLVIMENTISMO NEOEXTRATIVISTA E A COSMOVISÃO INDIGENA: O POLÊMICO PROJETO DA RODOVIA CORTANDO O TIPNIS NA BOLÍVIA

Liton LANES PILAU SOBRINHO CLEIDE CALGARO THIAGO DOS SANTOS DA SILVA

por conta de todo o levante social contrário ao projeto, o presidente Morales promulgou a Ley $180^{48}$, determinando o TIPNIS como território intangível.

Por alguns anos o projeto de rodovia sobre o TIPNIS permaneceu inerte, exatamente pela recepção nada favorável à obra. Porém, em agosto de 2017, o presente Evo Morales reacendeu a discussão, com um projeto de lei ${ }^{49}$ que permite a realização de projeto dentro do TIPNIS, o que significa retirar o caráter de intangibilidade que havia sido referido em 2011.

Os oponentes ao projeto realizaram denúncia formal ao Tribunal Internacional dos Direitos da Natureza, que ainda não proferiu decisão sobre o caso do TIPNIS, contudo, já teve sua jurisdição negada pelo Procurador-Geral do Estado boliviano, Pablo Menacho ${ }^{50}$.

O que se observa é que o governo boliviano, de forma contrária à sua retórica eleitoral, apoia seus projetos de políticas públicas de desenvolvimento em um crescimento econômico, guiando-se por práticas extrativistas, ou neoextrativistas, cindindo o "pacto" realizado com as bases sociais do país, quando da eleição do presidente Evo Morales. Portanto, é necessário desconstruir essa relação entre capital e desenvolvimento, como se o simples acréscimo de valores fosse suficiente para garantir o desenvolvimento humano e social de uma sociedade.

La carretera infame, como os povos originários do TIPNIS denominaram a rodovia proposta pelo Governo, por ora, está em estado suspenso. Porém, as movimentações do Governo boliviano demonstram que uma nova rodada de negociações poderá sobrepujar as questões sociais e da cosmovisão indígena, em favor de um desenvolvimentismo neoextrativista.

\section{CONCLUSÃO}

O presente trabalho foi guiado pela análise do projeto de rodovia proposta pelo Governo boliviano, que deve ligar as cidades de Villa Tunari e San Ignácio de Moxos, passando por dentro do Território Indígena e Parque Nacional Isibóro Sécure, terra comunitária de origem das nações indígenas Moxeña, Yuracaré e Chimán, no coração da Amazônia boliviana.

\footnotetext{
${ }^{48}$ Ver item 4.

49 Ley 979. Ver: Asambleia respalda demanda contra la ley del TIPNIS. Página Siete. Disponível em: http:/ / www.paginasiete.bo/nacional/2017/10/20/asamblea-respalda-demanda-contra-tipnis156425.html. Acesso em 15 fev. 2018.

50 CORREO DEL SUR. Procurador: Tribunal sobre el TIPNIS no fue reconocido. 2017. Disponível em: http://correodelsur.com/politica/20171125_procurador-tribunal-sobre-el-tipnis-no-fue-reconocido.html. Acesso em 15 fev. 2018.
} 
ISSN 1981-3694

(DOI): $10.5902 / 1981369438606$

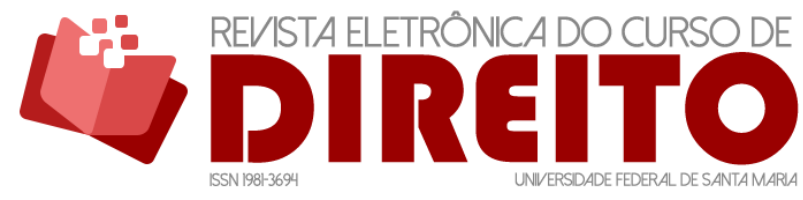

POLÍTICA PÚBLICA, DESENVOLVIMENTISMO NEOEXTRATIVISTA E A COSMOVISÃO INDÍGENA: O POLÊMICO PROJETO DA RODOVIA CORTANDO O TIPNIS NA BOLÍVIA

Liton LANES PILAU SOBRINHO CLEIDE CALGARO

THIAGO DOS SANTOS DA SILVA

Considerando o problema de pesquisa estabelecido, observa-se que a hipótese inicial formulada foi confirmada, qual seja, o Governo Morales, a despeito de sua retórica nacionalista e voltada aos direitos dos povos originários e sua cosmovisão, que pregava uma renúncia ao modelo desenvolvimentista de cunho eurocêntrico, via extrativismo, está implementando políticas públicas de cunho colonial e, notadamente, neoextrativista, no que tange ao crescimento econômico como modelo buscado de desenvolvimento.

É possível observar que parte da motivação para a referida obra é a IIRSA (Integração da Infraestrutura Regional Sul-americana), projeto continental implementado em 2000, após reunião realizada em Brasília, que estabeleceu uma série de metas e projetos a serem realizados pelos Estados sul-americanos. Com seu ápice em meados dos anos 2000 e 2010, a IIRSA, guiada principalmente pelo Brasil, deu azo a uma série de políticas públicas sob a justificativa de desenvolvimento regional, mas que, como a estrada pelo TIPNIS, tem uma base estritamente economicista.

Não há mais espaço para ligar crescimento econômico com desenvolvimento, visto que há claro caráter falacioso no discurso desenvolvimento extrativista, de caráter colonial e que observa o ambiente como recursos à disposição da economia, entre esses recursos, estão os seres humanos. Enquanto não exsurgir um projeto de desenvolvimento lastreado em relações éticas entre homem e natureza, não será superada a falácia econômica movimentada pelo mercado e implementada pelos Estados.

\section{REFERÊNCIAS}

ACOSTA, Alberto. El buen (con)vivir, una utopía por (re)construir: alcances de la constitución de Montecristi. Obets. Revista de Ciencias Sociales. Vol. 6, n. ${ }^{\circ}$ 1, 2011, pp. 35-67.

ALMEYRA, Guillermo. La Bolívia del TIPNIS: neodesarrollismo extractivista o alternativa al capitalismo. La jornada. Out. 2011. Disponível em:

http://www.jornada.unam.mx/2011/10/23/opinion/022a1pol. Acesso em 13 fev. 2018.

ALVES, Diógenes S. An analysis of the geographical patterns of deforestation in Brazilian Amazônia in the 1991-1996 period. University Presses of Florida, 2001, p. 95-111. Disponível em:

https://www.researchgate.net/publication/247152468_An_analysis_of_the_geographical_patter ns_of_deforestation_in_Brazilian_Amazonia_in_the_1991-1996_period. Acesso em $14 \mathrm{fev} .2018$.

BOLÍVIA. Constitución Política del Estado. 2009. Disponível em:

https://www.oas.org/dil/esp/Constitucion_Bolivia.pdf. Acesso em 02 fev. 2018. 
BOLÍVIA. Decreto Supremo № 22610. Disponível em: https: / www.lexivox.org/norms/BO-DS22610.xhtml. Acesso em 02 fev. 2018.

BOLÍVIA. Ley de protección del territorio indígena y parque nacional Isibóro Sécure - TIPNIS. 2011. Disponível em: http://www.somossur.net/documentos/Ley180corta_TIPNIS24102011.pdf. Acesso em 01 fev. 2018.

BOLÍVIA. Ley $\mathrm{n}^{\circ}$ 3477, 22 de septiembre de 2006. Disponível em: https://www.lexivox.org/norms/BO-L-3477.html. Acesso em 13 fev. 2018.

CORREO DEL SUR. Procurador: Tribunal sobre el TIPNIS no fue reconocido. 2017. Disponível em: http://correodelsur.com/politica/20171125_procurador-tribunal-sobre-el-tipnis-no-fuereconocido.html. Acesso em 15 fev. 2018.

DE MARZO, Giuseppe. Buen vivir: para una democracia de la Tierra. La Paz: Plural Editores, 2010.

EMBRAPA. Conhecendo espécies de plantas da Amazônia: mogno (Swietenia macrophylla KingMeliaceae). Disponível em: https://www.embrapa.br/busca-de-publicacoes//publicacao/1024143/conhecendo-especies-de-plantas-da-amazonia-mogno-swieteniamacrophylla-king--meliaceae. Acesso em 03 fev. 2018.

GUDYNAS, Eduardo. Buen vivir: un relanzamiento necesario. 2010, p. 2. Disponível em: http://www.sinpermiso.info/printpdf/textos/buen-vivir-un-relanzamiento-necesario. Acesso em 06 fev. 2018.

HOLLENDER, Rebecca. Política ambiental de los países “progresistas” en Latinoamerica: Buen vivir vs. Neo extractivismo. ALAI, ago. 2012. Disponível em:

http: //alainet.org/active/59393\&lang=pt. Acesso em 13 fev. 2018.

MEDIUM. A mão invisível do BNDES na América Latina. 2015, online. Disponível em: https: / / medium.com/brio-stories/a-m\%C3\%A3o-invis\%C3\%ADvel-do-bndes-na-am\%C3\%A9ricalatina-81bfcd8154a9. Acesso em 13 fev. 2018.

ORGANIZAÇÃO INTERNACIONAL DO TRABALHO. Convenção $\mathrm{n}^{\circ} 169$ sobre povos indígenas e tribais. 1989. Disponível em:

http://portal.iphan.gov.br/uploads/ckfinder/arquivos/Convencao_169_OIT.pdf. Acesso em 13 fev. 2018.

PROGRAMA DE INVESTIGACIÓN ESTRATÉGICA EN BOLIVIA. Viabilidad económica e institucional para el desarrollo de iniciativas que reduzcan la deforestación en el Territorio Indígena y Parque Nacional Isibóro Sécure. Disponível em:

http://www.pieb.com.bo/sipieb_nota.php?idn=5541. Acesso em 15 fev. 2018.

RIOS, Maria Teresa Vargas; RIVERO, Noelia Garzón; RICO, Edil Osinaga; MULLER, Robert. Compensación por servicios ambientales de carbono: una alternativa para reducir la deforestación en el TIPNIS. La Paz: Embajada Real de Dinamarca; Fundación PIEB, 2012. 
POLÍTICA PÚBLICA, DESENVOLVIMENTISMO NEOEXTRATIVISTA E A COSMOVISÃO INDIGGENA: O POLÊMICO PROJETO DA RODOVIA CORTANDO O TIPNIS NA BOLIVIA

Liton LANES PILAU SOBRINHO CLEIDE CALGARO

THIAGO DOS SANTOS DA SILVA

VITERI, María Amelia. Diagnóstico de la fragilidad de ecosistemas de bosque nativo con criterio ambiental. Chile Florestal, n. 258, 1998, p. 20-21. Disponível em: http: / / biblioteca.infor.cl/index.asp?param=0\%AD\%88\%92bh\%97\%8Fo\%5D\&Op=12. Acesso em 14 fev. 2018.

SERNAP. Servicio Nacional de Áreas Protegidas. Plan de Manejo del TIPNIS. 2005. Disponível em: http://sernap.gob.bo/index.php/areas-protegidas/area-natural-de-manejo-integrado/46-areasprotegidas/parque-nacional-y-territorio-indigena/60-isiboro-secure?showall=1\&limitstart=. Acesso em 03 fev. 2018.

Recebido em: 18.06.2019 / Revisões requeridas em: 09.08.2019 / Aprovado em: 14.08.2019 / Publicado em: 27.08.2019

\section{COMO FAZER REFERÊNCIA AO ARTIGO (ABNT):}

PILAU SOBRINHO, Liton Lanes; CALGARO, Cleide; SILVA, Thiago dos Santos da. Política pública, desenvolvimentismo neoextrativista e a cosmovisão indígena: o polêmico projeto da rodovia cortando o TIPNIS na Bolívia. Revista

Eletrônica do Curso de Direito da UFSM, Santa Maria, RS, v. 14, n. 2, e38606, maio./ago. 2019. ISSN 1981-3694. DOI: http://dx.doi.org/10.5902/1981369438606. Disponível em:

https://periodicos.ufsm.br/revistadireito/article/view/38606 Acesso em: dia mês. ano.

Direitos autorais 2019 Revista Eletrônica do Curso de Direito da UFSM

Editores responsáveis: Rafael Santos de Oliveira e Angela Araujo da Silveira Espindola

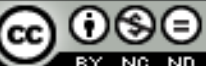

Esta obra está licenciada com uma Licença Creative Commons Atribuição-NãoComercial-SemDerivações 4.0 Internacional.

\section{SOBRE OS AUTORES}

Liton Lanes PILAU SOBRINHo

Professor dos cursos de Mestrado e Doutorado no Programa de Pós-Graduação Stricto Sensu em Ciência Jurídica da Universidade do Vale do Itajaí. Professor do Programa de Pós-Graduação Stricto Sensu Mestrado em Direito da Universidade de Passo Fundo.Coordenador do PPGDireito da Universidade de Passo Fundo. Pós-doutor em Direito pela Universidade de Sevilha - US. -Espanha. Doutor em Direito pela Universidade do Vale do Rio dos Sinos - UNISINOS (2008), Mestre em Direito pela Universidade de Santa Cruz do Sul - UNISC (2000). Possui graduação em Direito pela Universidade de Cruz Alta (1997). Tem experiência na área de Direito, com ênfase em Direito Internacional ambiental,Direito Constitucional.

\section{CLeide Calgaro}

Doutora em Ciências Sociais na linha de pesquisa "Atores Sociais, Políticas Públicas, Cidadania" (2013) pela Universidade do Vale do Rio dos Sinos (UNISINOS). Pós-Doutora em Filosofia (2015) e em Direito (2016) ambos pela Pontifícia Universidade Católica do Rio Grande do Sul (PUCRS). Doutoranda em Filosofia na linha de pesquisa "Ética e Filosofia Política" pela Pontifícia Universidade Católica do Rio Grande do Sul (PUCRS), na condição de taxista CAPES. Mestra em Direito na linha de pesquisa "Direito Ambiental e Biodireito" (2006) e Mestra em Filosofia na linha de pesquisa "Problemas Interdisciplinares de Ética" (2015) ambos pela Universidade de Caxias do Sul (UCS). Bacharela em Direito (2001) e em Filosofia (2018) pela Universidade de Caxias do Sul (UCS). Atualmente é Professora e pesquisadora no Programa de Pós-Graduação - Mestrado e Doutorado - e na Graduação em Direito da Universidade de Caxias do Sul. É líder do Grupo de Pesquisa "Metamorfose Jurídica", vinculado a Área de Conhecimento das Ciências Jurídicas e Mestrado/Doutorado em Direito da Universidade de Caxias do Sul (UCS). É vice-líder no Grupo de Pesquisa "Filosofia do Direito e Pensamento Político" da Universidade Federal da Paraíba-UFPB e atua como pesquisadora no Grupo de pesquisa "Regulação ambiental da atividade econômica sustentável (REGA)" da Escola Superior Dom Helder Câmara. Também, atua no CEDEUAM UNISALENTO - Centro Didattico Euroamericano 
ISSN 1981-3694

(DOI): $10.5902 / 1981369438606$

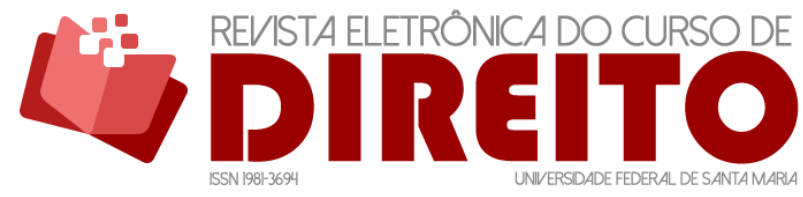

POLÍTICA PÚBLICA, DESENVOLVIMENTISMO NEOEXTRATIVISTA E A COSMOVISAOO INDIGENA: O POLEMICO PROJETO DA RODOVIA CORTANDO O TIPNIS NA BOLÍVIA

LiTON LANES PILAU SOBRINHO CLEIDE CALGARO

THIAGO DOS SANTOS DA SILVA

sulle Politiche Costituzionali na Università del Salento-Itália. Desenvolve pesquisa a partir de um viés interdisciplinar nas áreas de Direito, Ciências Sociais e Filosofia, atuando principalmente nos seguintes temas: Direito Socioambiental; Meio Ambiente; Constitucionalismo Latino-americano; Constituição, Democracia e Direitos Fundamentais; Relação de Consumo e Hiperconsumo; Filosofia Política e Social.

THIAGO dos SANTOS dA SILVA

Graduado em Direito pela Universidade Regional do Noroeste do Estado do Rio Grande do Sul (2010). Mestre em Direito pela Universidade Regional do Noroeste do Estado do Rio Grande do Sul (2016). Doutorando em Direito pela Universidade de Caxias do Sul. Atualmente é advogado, com ênfase em Direito Familiar e Direito Penal. Professor do Curso de Graduação em Direito na Universidade Regional do Noroeste do Estado do Rio Grande do Sul/UNIJUÍ, na área de Direito, Processo e Prática Penal 